FEDERAL

RESERVE

BANK of

ST. LOUIS

\section{RESEARCH DIVISION} Working Paper Series

\title{
International Channels of the Fed's Unconventional Monetary Policy,
}

\author{
Michael D. Bauer \\ and \\ Christopher J. Neely
}

Working Paper 2012-028D

https://doi.org/10.20955/wp.2012.028

December 2013

\section{FEDERAL RESERVE BANK OF ST. LOUIS \\ Research Division \\ P.O. Box 442}

St. Louis, MO 63166

The views expressed are those of the individual authors and do not necessarily reflect official positions of the Federal Reserve Bank of St. Louis, the Federal Reserve System, or the Board of Governors.

Federal Reserve Bank of St. Louis Working Papers are preliminary materials circulated to stimulate discussion and critical comment. References in publications to Federal Reserve Bank of St. Louis Working Papers (other than an acknowledgment that the writer has had access to unpublished material) should be cleared with the author or authors. 


\title{
International Channels of the Fed's Unconventional Monetary Policy*
}

\author{
Michael D. Bauer ${ }^{\dagger}$ Christopher J. Neely
}

December 12, 2013

\begin{abstract}
Previous research has established that the Federal Reserve's large scale asset purchases (LSAPs) significantly influenced international bond yields. We use dynamic term structure models to uncover to what extent signaling and portfolio balance channels caused these declines. For the U.S. and Canada, the evidence supports the view that LSAPs had substantial signaling effects. For Australian and German yields, signaling effects were present but likely more moderate, and portfolio balance effects appear to have played a relatively larger role than in the U.S. and Canada. Portfolio balance effects were small for Japanese yields and signaling effects basically nonexistent. These findings about LSAP channels are consistent with predictions based on interest rate dynamics during normal times: Signaling effects tend to be large for countries with strong yield responses to conventional U.S. monetary policy surprises, and portfolio balance effects are consistent with the degree of substitutability across international bonds, as measured by the covariance between foreign and U.S. bond returns.
\end{abstract}

Keywords: monetary policy, zero lower bound, LSAP, signaling, portfolio balance, dynamic term structure model

JEL Classifications: E43, E52

${ }^{*}$ The views expressed in this paper are those of the authors and do not necessarily reflect those of Federal Reserve Banks of San Francisco or St. Louis or the Federal Reserve System.

${ }^{\dagger}$ Federal Reserve Bank of San Francisco, 101 Market St. MS 1130, San Francisco, CA 94105, USA; e-mail: michael.bauer@sf.frb.org.

${ }^{\ddagger}$ Federal Reserve Bank of St. Louis, Box 442, St. Louis, MO 63166-0442, USA; e-mail: neely@stls.frb.org. 


\section{Introduction}

In response to the extreme credit market disturbances in the fall of 2008, the Federal Reserve lowered the Federal funds rate target to near-zero, announced unprecedented bond purchases, and offered forward guidance to markets to reduce expectations of future short rates. Eventually, the Fed would announce three rounds of asset purchases that would total over $\$ 3$ trillion from November 2008 through 2013. Federal Open Market Committee (FOMC) statements and speeches described the motives for these asset purchases in several ways but repeatedly returned to the themes of directly supporting credit markets - especially for housing - to reduce medium- and long-term U.S. interest rates in order to ultimately stimulate real activity. Other central banks, that is, the Bank of Japan, the Bank of England and the European Central Bank, would later initiate or expand similar programs. A growing literature studies the empirical effects of these unconventional policies. For the United States, the event study estimates of Gagnon et al. (2011) and Krishnamurthy and Vissing-Jorgensen (2011) establish that the Fed's asset purchases strongly affected domestic bond yields. Neely (2013) finds that the purchases had substantial international effects on bond and foreign exchange markets.

Announcements of large scale asset purchases (LSAPs) can affect government bond yields through both signaling and portfolio balance channels. The signaling channel implies that investors interpret asset purchase announcements as implying a lower path for future shortterm interest rates, which reduces the expectations component of long-term interest rates. ${ }^{1}$ On the other hand, asset purchases can also affect prices of imperfectly substitutable assets through the portfolio balance channel. A purchase of U.S. bonds can reduce the term premia in both U.S. long-term yields and in international substitutes.

A crucial question is how important signaling and portfolio balance channels are empirically for the effects of these asset purchases on government bond yields. For the U.S., the term

\footnotetext{
${ }^{1}$ The announcements can contain both direct (explicit) and indirect (implicit) signals about the future shortrate path (Woodford, 2012). The event study approach chosen here and in other papers cannot distinguish between these.
} 
structure estimates of Gagnon et al. (2011) appear to indicate that portfolio balance effects dominate, and these authors conclude that the signaling effects are negligible. On the other hand, Bauer and Rudebusch (2013b) and Christensen and Rudebusch (2012) find a substantially larger role for the signaling channel of asset purchase announcements. ${ }^{2}$ Neely (2013) argues that the large impact of the Fed's LSAP announcements on international yields are consistent with a portfolio balance effect but he does not directly evaluate the relative importance of signaling/portfolio balance effects. There has been no serious analysis of the channels through which the Fed's LSAP announcements affected international bond yields. This paper aims to fill that gap by using term structure models to evaluate the relative importance of LSAP channels in mediating the impact of the Fed's asset purchases on international bond yields. In addition to U.S. yields, we study the effects on interest rates in Canada, Germany, Australia, and Japan. ${ }^{3}$ We consider announcements associated with the three LSAP programs during the period from 2008 to 2012: QE1, QE2, and QE3.

Before presenting our results on the relative importance of LSAP channels of unconventional policy, we investigate what past data would lead us to expect for each country. We predict the impact of U.S. LSAPs on expectations of foreign short-term interest rates by analyzing how conventional U.S. monetary policy surprises affect foreign yields. For example, the strong reaction of Canadian yields to conventional U.S. monetary shocks implies a significant signaling effect for that country's markets. Analysis of the covariances between real foreign and U.S. bond returns predict that Australia and Germany would show the strongest portfolio balance channel effects.

Using dynamic term structure models (DTSMs) we estimate changes in short-rate expectations and term premia around key LSAP announcements. Their respective contribution to

\footnotetext{
${ }^{2}$ Joyce et al. (2011) cite swap rates to argue that the Bank of England's purchases worked mainly through the portfolio balance channel. Christensen and Rudebusch (2012) confirm the importance of portfolio balance effects on domestic government yields.

${ }^{3}$ We omit the U.K. from our analysis because news unrelated to U.S. policies significantly influenced U.K. short-term interest rate movements during the policy event windows. These movements distorted measurement of the effect of U.S. unconventional policies on the U.K., but not other bond markets.
} 
the observed decreases in long-term yields is a measure of the importance of the signaling and portfolio balance channels. Importantly, changes in short-rate expectations should be viewed as conservative estimates of the importance of the signaling channel for two reasons: First, a successful monetary policy action aimed at easing financial conditions stimulates future growth and would raise short-rate expectations for the more distant future, counteracting the decreases in expectations due to signaling effects. Second, signaling near-zero policy rates would tend to lower interest rate risk and the term premium, even without any portfolio balance effects. $^{4}$

The resulting inference can be quite sensitive to model choice. To guard against modeldependent conclusions and to obtain robust evidence, we estimate six alternative models for each country. In addition to a conventional maximally-flexible model, we correct for smallsample bias and restrict model parameters to obtain more reliable results. We evaluate the term structure models using criteria that include out-of-sample forecast accuracy. Models that impose greater peristence on the expected short rate or that restrict the dynamic evolution of the risk factors (as in Duffee, 2011) have the best forecasting performance. Based on the forecast accuracy, we can weight well-performing models more heavily, and can partly address the issue of model uncertainty.

We find that the unconventional policy announcements had the most substantial signaling effects for the U.S. and Canada. In both countries, changes in expected future policy rates contributed significantly to lower long-term yields in those two countries. This finding holds for all three LSAP programs. The strong signaling effects on Canadian rates is consistent with the sensitivity of Canadian interest rates to signals from conventional U.S. monetary policy surprises. Overall, signaling effects likely accounted for a very substantial part of the sizable effects of the Fed's LSAP announcements on U.S. and Canadian long rates.

For Australia and Germany, we also find strong signaling effects. They appear slightly more moderate than for the U.S. and Canada, however, and these estimates entail model

\footnotetext{
${ }^{4}$ See also Bauer and Rudebusch (2013b) and Woodford (2012) for similar arguments.
} 
uncertainty. Again, the results are quite consistent across the three LSAP programs. ${ }^{5}$. In these countries, portfolio balance effects probably played a relatively larger role than they did for the U.S. and Canada, which is consistent with the predictions based on interest rate dynamics during normal times.

For Japan, signaling effects are negligibly small and portfolio balance effects can entirely explain the modest LSAP announcement effects. ${ }^{6}$ A very weak signaling channel parallels the weak reaction of Japanese yields to conventional U.S. monetary policy and the small portfolio balance effects are consistent with the relatively weak covariance between Japanese and U.S. long bond returns.

This paper is part of a quickly growing literature on the effects of unconventional monetary policies on financial markets. In addition to the event studies of the LSAPs cited above, other papers include Joyce et al. (2011), D'Amico and King (2013), D'Amico et al. (2012), Hamilton and Wu (2012), and Li and Wei (2013). Our paper is also related to the literature on the effects of (conventional) U.S. monetary policy surprises on international asset prices (Andersen et al., 2003; Faust et al., 2007; Ehrmann and Fratzscher, 2009; Ammer et al., 2010). Two papers in particular study spillovers of conventional monetary policy surprises on international yields: Craine and Martin (2008) find that U.S. monetary policy surprises affect Australian interest rate and equity markets but Australian surprises do not measurably affect U.S. financial markets. Hausman and Wongswan (2011) establish that conventional U.S. policy surprises affect interest rates, equity prices, and exchange rates in 49 different countries. The strong effect on foreign interest rates that they document suggests a high potential for international signaling effects for U.S. monetary surprises, which is consistent with our findings. We extend this literature to study the channels through which unconventional policies affect international yields.

The paper is structured as follows: Section 2 discusses details of the Fed's first LSAP

\footnotetext{
${ }^{5}$ An exception is Germany during the QE3 episode, a case in which yields actually increased.

${ }^{6}$ The low initial level of Japanese yields also ikely contributed to the relatively modest (but perhaps economically meaningful) effect on these yields.
} 
program and the extent to which an event study approach can assess its effects on financial markets. Section 3 reviews the signaling and portfolio balance channels and predicts their relative importance with independent empirical evidence. Section 4 presents and discusses the DTSMs that we use for our empirical analysis. Section 5 contains the empirical results on the importance of signaling and portfolio balance channels for international LSAP effects. Section 6 concludes.

\section{Event study of the Fed's first LSAP program}

Announcements related to the Federal Reserve's three rounds of the LSAP program, also commonly known as "QE1," "QE2," and "QE3" (quantitative easing), consisted of suggestions of possible future purchases, firm statements of planned purchases, including time-frames and quantities, and announcements of reductions or slowdowns of purchases. These announcements changed market expectations of future asset purchases by the Fed and, consistent with the efficient market hypothesis, immediately affected asset prices. Therefore, we apply the widely used event study approach to assess and analyze the impact of the announcements associated with the LSAP programs - 2008 to 2012 - on yields in the U.S., Canada, Japan, Germany, and Australia. ${ }^{7}$

\section{$2.1 \quad$ Event study approach}

The approach chosen here considers changes in asset prices around narrowly chosen event windows to estimate the relative importance of the signaling and portfolio balance channels to the total effect on international long bond yields. ${ }^{8}$

\footnotetext{
${ }^{7}$ Here we focus on the announcements and their news content. Gagnon et al. (2011) describe the actual implementation of QE1 in detail. Fawley and Neely (2013) describe the circumstances of and motivations for the whole quantitative easing programs of the Federal Reserve, the Bank of England, the European Central Bank, and the Bank of Japan.

${ }^{8}$ Many studies analyze the effects of QE1 using an event study methodology are Gagnon et al. (2011), Joyce et al. (2011), Neely (2013), and Bauer and Rudebusch (2013b). At least two studies also consider some effects from QE2, Glick and Leduc (2012), Rosa (2012). An advantage of the event study approach is that
} 
Most event studies seek to determine the effect of the unexpected component of some event - e.g. a monetary policy announcement or macroeconomic release - on prices. However, for LSAPs it is challenging to identify all events that affected market expectations about future purchases. For example, in the case of QE2 and QE3, expectations for further Fed asset purchases built up over time before any official policy announcements took place. This makes it difficult to estimate the total effects of LSAP surprises on asset prices using the event study approach.

Fortunately, our goal here is not to estimate the total effects of LSAPs on asset prices, but instead to gauge the relative contributions of the signaling and portfolio balance channels. Therefore, we do not need to fully capture all LSAP surprises or identify the surprise component of each announcement. Instead, we just need the announcements to contain some surprise about asset purchases which affects interest rates. We can then assess what proportion of interest rate changes were due to movements in expected future short rates and term premia. While our estimates most likely do not capture the total impact of each program, because the event sets are surely missing some important changes in expectations, they do capture the relative importance of signaling and portfolio balance channels for our LSAP events.

Event studies must also assume that the net effect of other news during the event windows is negligible, relative to the magnitude of the policy news effects. Intraday analysis of asset prices in Neely (2013) confirms that policy news dominates the non-policy news during the event windows: The large daily price changes typically occurred during a tight window around the Fed's policy announcements. For the five countries in our event study, there were several news reports during the event windows that potentially affected yields. ${ }^{9}$ However, closer

it does not require the policy interventions to be truly exogenous but merely predetermined with regard to the event window. The main alternative approach is a time series analysis of interest rates and variables measuring the supply of the targeted securities - see, for example, Li and Wei (2013) and Hamilton and Wu (2012) - which, however, by construction can only provide estimates of portfolio balance effects and does not capture signaling effects.

${ }^{9}$ For example, there was a CPI release in the U.S. on December 16, 2008 and an announcement about asset purchases by the Bank of Japan on March 18, 2009. 
examination of these events and their timing, including the study of intraday asset price responses to these news, suggests that - with one exception - such news had marginal net effect on interest rates that do not unduly bias our estimates of the LSAP channels' importance. ${ }^{10}$

The U.K. experienced some significant news during the event windows that was unrelated to U.S. monetary policy, including several pieces of bad macro news and an announcement that the government would back retail bank deposits. Although the effects of these events can be distinguished from U.S. policy announcement effects with high frequency data, this is not possible in our term structure analysis of daily zero-coupon yields. Therefore we exclude the U.K. from our analysis.

\subsection{Events}

What events influenced expectations of unconventional policies? In selecting the event days, we considered the events that have been included in other prominent event studies, but we also aim for homogeneous event sets and therefore focus on days on which the Fed seems to have increased expected purchases and reduced the level of the yield curve. ${ }^{11}$ We ultimately selected nine events, described in Table 1, that contained substantial LSAP surprises. For QE1, we consider the four LSAP announcements that constituted an expansionary monetary policy surprise according to the intraday policy surprise measure constructed by Wright (2012). This event set is more homogeneous than the QE1 event sets studied by others, for example by Gagnon et al. (2011) and Krishnamurthy and Vissing-Jorgensen (2011). In particular, it excludes January 28, 2009, a day on which the Fed failed to announce a purchase, disappointing markets and raising yields significantly. Although we omit full results for brevity, our inference is essentially unchanged by expanding our QE1 event set to include other important dates,

\footnotetext{
${ }^{10}$ The exception is that Germany experienced yield changes on September 13, 2012 that appear to be unrelated to U.S. monetary policy news but were due to news about ECB purchases of Eurozone debt. We note this issue in the discussion of the German results. A fuller discussion is available from the authors but is omitted here for brevity.

${ }^{11}$ The events we consider were also studied by Gagnon et al. (2011), Neely (2013), Bauer and Rudebusch (2013b), Krishnamurthy and Vissing-Jorgensen (2011), Glick and Leduc (2012), and Rosa (2012).
} 
such as January 28, 2009, or the full set of eight QE1 announcements studied by Gagnon et al. (2011). For the second LSAP program, QE2, we include the three events that were studied by Krishnamurthy and Vissing-Jorgensen (2011), and exclude, like most other studies, Chairman Bernanke's Jackson Hole speech on August 27, 2010, which did not reduce yields. For QE3, we consider the two main announcements on August 22, 2012, and on September 13, 2012.

We focus on daily changes in government bond yields and their model-implied components around the announcements. We must take care with the timing, however, because the yield data for each country may be collected at different times of day and the LSAP events can vary in timing as well. For the U.S. and Canada, the difference in yields from day $t-1$ to day $t$ (the announcement day) encompasses the announcement. For Australia and Japan, bond yield data for the announcement day were always collected prior to the announcements, so we calculate the change from $t$ to $t+1$. For Germany, we consider yield changes from $t$ to $t+1$ for all announcements but the first one - the initial LSAP announcement on November 25, 2008, occurred at 8:15am EST, prior to the collection of yield data in European bond markets, so no offset is necessary. ${ }^{12}$

\section{International signaling and portfolio balance channels}

Central bank asset purchases can potentially affect the prices of government bonds through signaling and portfolio balance channels. ${ }^{13}$ This section defines and explains these two channels, in both the domestic and international context, and presents empirical predictions of their respective importance for the Fed's LSAP announcements on international yields.

\footnotetext{
${ }^{12}$ The intradaily interest rate movements for QE1 documented in Neely (2013) support these timing assumptions.

${ }^{13}$ LSAPs can potentially affect asset prices through other channels as well, for example, by affecting liquidity and credit risk. For example, the first round of the Fed's LSAPs improved the liquidity and market functioning in mortgage-backed securities by providing a consistent source of demand (Gagnon et al., 2011) and likely lowered credit risk premia in corporate bond markets (Krishnamurthy and Vissing-Jorgensen, 2011). For Treasury securities, a market with extraordinarily high liquidity and nearly no credit risk, we can safely focus signaling and portfolio balance effects.
} 
In distinguishing the two channels, it is useful to define the expectations component and the term premium in a long-term government bond yield:

$$
y_{t}^{n}=n^{-1} \sum_{i=0}^{n-1} E_{t} r_{t+i}+Y T P_{t}^{n} \text {, }
$$

where $y_{t}^{n}$ is the yield at time $t$ on an $n$-period bond, $r_{t}$ is the short-term interest rate (i.e., the policy rate), the first term on the right-hand side is the average expected overnight rate over the subsequent $n$ periods, and $Y T P_{t}^{n}$ is the yield term premium. The expectations component captures the marginal investor's expectations of future monetary policy. The term premium captures the additional compensation for the interest rate (duration) risk inherent in long-term bond positions, as well as residual effects from market segmentation or other frictions.

\subsection{Signaling}

The signaling channel recognizes that central bank announcements can affect long-term interest rates by signaling a path for future policy rates. ${ }^{14}$ An asset purchase announcement will generally communicate a more accommodative (lower) path of the future policy rate.

Central bank announcements can convey information about the path of the future policy rate both directly and indirectly. The Fed provided direct (explicit) signals, in the form of explicit forward guidance, in two FOMC statements that also contained LSAP announcements. On December 16, 2008, the FOMC cut the target for the policy rate to near zero and indicated that it expected "exceptionally low levels of the federal funds rate for some time." On March 18, 2009, the FOMC changed its language to indicate that it expected "exceptionally low levels of the federal funds rate for an extended period."

Asset purchase announcements can contain indirect (implicit) signals for several reasons. First, such announcements can convey to the public that the central bank forecasts weaker inflation and/or slower real growth than the consensus. For a given policy rule, this would

\footnotetext{
${ }^{14}$ This definition is in line with those used in other studies (Gagnon et al., 2011; Woodford, 2012).
} 
then imply lower future policy rates. Second, the fact that the central bank intends to pursue unconventional monetary policies could suggest that it will pursue a more accommodative policy stance more generally. This could mean either changing the policy rule, or temporarily deviating from normal policy by keeping short-term rates unusually low for a long time. ${ }^{15}$

How can we understand signaling effects in the context of the yield decomposition in equation (1)? We estimate the importance of the signaling channel by the changes in short-rate expectations around LSAP events, as is common in event studies of LSAPs. Such estimates will include the effects of both direct and indirect signals, which would be very difficult to separately identify. ${ }^{16}$

One should note that changes in short-rate expectations likely underestimate the importance of signaling effects. To the extent that asset purchase announcements produce a better economic outlook, they would marginally raise policy-rate expectations for the distant future, which would partly offset decreases in the expected policy path signaled by the Fed. Therefore, measured changes in policy expectations would conservatively estimate the importance of the signaling channel (see also Bauer and Rudebusch, 2013b).

Here we are interested in how the Fed's LSAP announcements lowered international yields, and hence international signaling effects. Why might announcements about a U.S. asset purchase program provide information about the future monetary policy of a foreign central bank? In practice, central bank policy rates can be correlated internationally for various reasons, especially for countries with close economic ties. Central banks often respond similarly to common global surprises, e.g., changes in commodity prices or financial conditions. Furthermore, exchange rate stabilization might require that a central bank follow another country's monetary policy.

Empirically, Craine and Martin (2008) document that U.S. monetary policy surprises strongly

\footnotetext{
${ }^{15}$ A strategy that promises to deviate from normal policy is what Eggertson (2006) refers to as "committing to be irresponsible."

${ }^{16}$ It does not help to consider only a subset of events because the asset purchase news and forward guidance (direct signals) were coincident. For example, the announcements on December 16, 2008 and on March 18, 2009, contained both forward guidance and important information about the LSAP program.
} 
influence Australian asset prices and Hausman and Wongswan (2011) find that U.S. monetary policy surprises explain yield changes in many countries. This evidence indicates that current and expected future policy rates abroad react to U.S. monetary policy actions and signals. ${ }^{17}$ Hence, unconventional policy announcements by the Fed might well change expectations of future policy rates abroad.

We expect signaling effects to be larger for those countries whose interest rates have historically reacted strongly to U.S. monetary policy surprises. To assess this relationship, we regress changes in foreign interest rates on measures of U.S. "target" and "path" monetary policy surprise measures, as defined by Gürkaynak et al. (2005). These extend the one-dimensional policy surprise measure of Kuttner (2001). The target and path variables reflect surprises about the current federal funds rate target and new information about its intended future path, respectively. Gürkaynak et al. (2005) show that policy surprises strongly affect long-term yields while Hausman and Wongswan (2011) apply this method to show that U.S. monetary policy surprises also affect foreign yields. ${ }^{18}$ We construct target and path surprises with data on Eurodollar futures prices from Tickwrite and Federal funds futures prices from the Wall Street Journal. Haver and Bloomberg provide daily data on international zero coupon yields. Our sample consists of 139 policy announcements from February 1, 1995 to March 15, 2011. ${ }^{19}$

Table 2 shows the results from regressing one-day interest rate changes on policy days on the policy surprise measures. The path surprises have statistically significant, positive effects on all foreign yields except three-month Japanese yields. Similarly, target surprises significantly raise Canadian and German 3-month yields and Australian, Canadian and German two-year yields. U.S. monetary policy has its strongest effects-based on $t$-statistics and $R^{2} s$ - on

\footnotetext{
${ }^{17}$ There is less reason to believe that monetary policy actions abroad affect U.S. interest rates. Smaller countries are more likely to take external factors into account when making monetary policy because conditions in large countries, like the United States, affect conditions in smaller trading partners more than the reverse. Craine and Martin (2008) do not find any effects of Australian policy surprises on U.S. asset prices.

${ }^{18}$ Hausman and Wongswan (2011) use a slightly different procedure to construct target and path surprises, but report that alternative measures produce very similar results.

${ }^{19}$ Gürkaynak et al. (2005) publish the timing of FOMC press releases for meetings from January 1994 to December 2004, and Rosa (2012) provides the timing for meetings between May 1999 and June 2011.
} 
Canadian yields. Australian interest rates also show high coefficients and $t$-statistics on path surprises. The effects of U.S. policy shocks are weakest for Japan, which has had very low and fairly stable short term interest rates since 1995. Based on these results, we predict that the strongest international signaling effects of U.S. LSAP announcements will be on Canadian bond yields, followed by Australian and German yield responses, and that the weakest effects will be on Japanese bond yields.

\subsection{Portfolio balance}

The portfolio balance channel implies that central bank bond purchases will affect the term premium in long-term interest rates due to imperfect substitutability between securities of different maturities or asset classes. Market segmentation implies that the amount and maturity structure of outstanding government securities, which is affected by LSAPs, determine risk premia in long-term interest rates. Portfolio balance models suggest that investors have downward sloping demand for specific types of risk (e.g., duration risk) and therefore a reduction in the supply of an asset should reduce the required expected return on that asset and assets whose returns covary positively with it. ${ }^{20}$ Intuitively, if the LSAP raises U.S. bond prices, then investors will tend to substitute toward the now relatively underpriced debt of similar quality (domestic or international), driving up the price of that debt. This substitution will affect all securities whose returns covary positively with the purchased asset.

We will estimate the importance of the portfolio balance channel from the magnitude of changes in the term premium (see equation (1)) in long-term yields around LSAP announcements. However, estimated term premium changes likely overstate the importance of the portfolio balance channel: Signaling effects could cause part of the decrease in the term premium effects because lower future policy rates tend to decrease interest rate risk

\footnotetext{
${ }^{20}$ The literature has focused on portfolio balance effects through "duration removal" (i.e., the lowering of the total amount of interest rate risk), but D'Amico et al. (2012) have also established some direct price effects from "local scarcity" (i.e., purchases of specific securities which do not have any substitutes).
} 
(Bauer and Rudebusch, 2013b; Woodford, 2012). This is a second reason why decomposing yield changes into expectations and term premium effects leads to conservative estimates of the relative importance of the signaling channel.

This paper specifically examines international portfolio balance effects. The only real difference between domestic and international portfolio balance effects, however, is the need to compare expected asset returns in a common currency. Neely (2013) illustrates international portfolio balance effects through the portfolio choice of a budget-constrained, mean-variance investor who represents all agents except the Federal Reserve/U.S. government. An official asset purchase must change the public's portfolio weights through market clearing. A larger bond purchase or greater risk aversion will tend to reduce the expected returns of assets with positive covariance to the purchased asset. In the present case, one might expect a substantial portfolio balance effect from the very large asset purchases. Gagnon et al. (2011) estimate that the 1.725 trillion dollar total debt purchase of the first round of LSAPs constituted 22 percent of the publicly held, long-term agency debt, fixed-rate agency MBS, and Treasury securities that were outstanding as of November 24, 2008, just prior to the first LSAP announcement. QE2 and QE3 were also large. QE2 purchases were $\$ 600$ billion; QE3 purchases were $\$ 85$ billion per month, from late 2012 to the time of this writing in late 2013. A given purchase will produce greater portfolio balance effects on assets whose excess returns exhibit higher covariance with those of the officially purchased asset. Specifically, the expected excess dollar return of a foreign bond should change proportionally to the covariance between that bond's excess return and that of the U.S. bond..$^{21}$

To predict the importance of international portfolio balance effects for the Fed's LSAPs, we estimate the covariances of international excess bond returns with those of the United States. We construct monthly international excess bond returns using nominal 7-10 year Citigroup bond indices from Bloomberg, exchange rates at the New York close from the Wall Street

\footnotetext{
${ }^{21}$ Because the Fed controls the expected return on the liquid asset and it changed very little over event windows, the excess return will change similarly to the expected return on the foreign bond in dollars.
} 
Journal and 1-month Treasury rates from Haver, from January 1985 through April 2010. The covariances of these monthly excess bond returns for the U.S. versus Australia, Canada, Japan and Germany are 3.16, 2.62, 2.38 and 3.18, respectively. The corresponding correlations are $0.43,0.49,0.31$ and $0.46 .^{22}$ To the extent that changes in expected exchange rate returns are small or similar across countries, this suggests that a change in the U.S. portfolio weight will have the strongest portfolio balance effects on German and Australian returns and the weakest effects on Japanese returns.

\section{Model specification and estimation}

In order to decompose the changes in government bond yields on the announcement dates into expectations and term premium components, we estimate affine Gaussian DTSMs for the zero-coupon government bond yields of each country. ${ }^{23}$ Using six different models helps guard against model-specific conclusions. The affine models we use have the advantages that they (i) parsimoniously model the entire yield curve with a small number of risk factors, (ii) impose absence of arbitrage, enforcing consistency on the cross-sectional and time series behavior of yields, and (iii) are very tractable to estimate.

\subsection{Affine term structure models}

DTSMs have three basic ingredients: a time series model for the risk factors, an equation linking the short rate to the risk factors, and a specification of the stochastic discount factor (SDF) used to price bonds. In this paper we use discrete-time affine Gaussian models, hence

\footnotetext{
${ }^{22}$ Australian bond index data begins in October 1993 and the covariance is calculated for the sample starting at that date.

${ }^{23}$ An alternative approach would be to jointly model yields of five countries, but this would bring up a host of difficult issues, including the complication that daily yields from different countries are sampled at different times during the day. We consider country-level models as a useful and sufficiently rich modeling framework for our purpose.
} 
risk factors follow a first-order Gaussian VAR:

$$
X_{t+1}=\mu+\Phi X_{t}+\Sigma \varepsilon_{t+1}
$$

where $X_{t}$ is an $N$-vector of risk factors, $\varepsilon_{t} \stackrel{i i d}{\sim} N\left(0, I_{N}\right)$ and $\Sigma$ is lower triangular. The first three principal components of each country's yield data are the risk factors, $X_{t}$, that correspond to the level, slope, and curvature of the yield curve. ${ }^{24}$ We assume an SDF of the usual exponentially-affine form. Consequently, model-implied yields, short-rate expectations, and term premia are affine functions of the risk factors. We impose the normalization of Joslin et al. (2011), which concentrates many parameters out of the likelihood function. Appendix A provides details.

The VAR parameters, $\mu$ and $\Phi$, determine the properties of expected short rates and term premia but the high persistence of interest rates makes it hard to accurately estimate them (Kim and Orphanides, 2012; Bauer et al., 2012). Maximum likelihood (ML) estimates in an unrestricted DTSM typically lack precision and often exhibit substantial small-sample bias, making the estimated system less persistent than the true data-generating process. Because the estimated mean reversion of the short-rate is too rapid, forecasts of future short-term interest rates are too close to their unconditional mean and hence too stable. As a consequence, the term premium component explains too much variation in yields. When studying LSAPs using an event study methodology, an uncorrected model would therefore tend to underestimate the importance of changes in short-rate expectations and understate signaling effects - this is the main point of Bauer and Rudebusch (2013b). We address this downward bias in estimated VAR persistence in three ways: first, by directly correcting for the bias, as in Bauer et al. (2012); second, by imposing parameter constraints that increase persistence, as in Duffee (2011); and third, by restricting the risk pricing in the model, as in Cochrane and Piazzesi

\footnotetext{
${ }^{24}$ We have also estimated the models using four risk factors. The more parismonious three factor models forecasted better in out-of-sample exercises than did the four-factor specifications. Therefore we chose to use the former.
} 
(2008), Bauer (2011), and Joslin et al. (2012). ${ }^{25}$

OLS The baseline model is the maximally-flexible specification, estimated using ML. Conveniently, $\mu$ and $\Phi$ can be estimated using OLS (hence the model identifier) before the remaining parameters are found by maximizing the likelihood function (Joslin et al., 2011). This model will generally understate the persistence of the risk factors because of small-sample bias.

BC The bias-corrected (BC) model adjusts the OLS estimates for small-sample bias in the VAR parameters, using the two-stage methodology of Bauer et al. (2012). First, we correct estimates of $\mu$ and $\Phi$ for bias using a conventional bootstrap, applying the stationarity adjustment of Kilian (1998) to ensure the largest eigenvalue of $\Phi$ does not exceed unity. Second, we maximize the likelihood function over the remaining parameters for given values of $\mu$ and $\Phi$. This procedure implies a more persistent VAR process, and a comparison with the OLS model can provide estimates of the bias.

RW The random walk (RW) specification imposes a random walk without drift on the level factor. The slope and curvature factors are assumed not to predict the level factor and vice versa. That is, the upper-left element of $\Phi$ equals one and the other elements of the first row and first column equal zero. This model closely corresponds to the "PC-RW" model estimated in Duffee (2011), a yield-curve model which does not impose absence of arbitrage but has the same specification of the mean-reversion matrix.

UR The unit root (UR) specification restricts the VAR parameters to imply a unit root for the first risk factor and allow some predictability of changes in this factor. That is, the first column of $\Phi$ is equal to $(1,0,0)^{\prime}$ and the other elements are unrestricted. This model parallels the "PC-UR" model in Duffee (2011), which has the same mean-

\footnotetext{
${ }^{25}$ Restrictions on the risk adjustment, which ties the cross-sectional to the time series behavior of interest rates, have been advocated by these authors because they can reduce statistical uncertainty and mitigate the small-sample bias in the VAR parameter estimates.
} 
reversion matrix but does not impose absence of arbitrage. Duffee (2011) shows that his PC-RW and PC-UR models forecast monthly Treasury yields well, out-of-sample. ${ }^{26}$ Restricting the largest root of the VAR to one in the RW and UR models reduces estimation uncertainty and avoids the downward bias in the estimated persistence.

R-BIC The R-BIC model imposes zero restrictions on the risk sensitivity matrix $\left(\lambda_{1}\right.$, see Appendix A) in order to optimize the Bayesian Information Criterion (BIC). This approach is similar to that of Joslin et al. (2012).

R-CP This model restricts the rank of the risk sensitivity matrix to one; only one linear combination of $X_{t}$ drives risk prices. This is in the spirit of Cochrane and Piazzesi (2005), who find that one linear combination of forward rates explains most excess bond returns.

One issue of potential concern is that Gaussian DTSMs do not respect the zero lower bound (ZLB) on nominal interest rates. Some recent advances in DTSM modeling at the ZLB, including Kim and Singleton (2012) and Bauer and Rudebusch (2013a), might open up new possibilities, but explicitly incorporating the ZLB in models with daily yield data is computationally very costly. We can, however, assess the likely impact of the ZLB constraint by examining the paths for forward rates and expected paths for policy in our sample. While there are periods in our sample when interest rates were very close to zero, the forward curves and expected paths for future policy rates almost never drop below zero around the events that we consider. Therefore, it is unlikely that the ZLB substantially affects our results.

\subsection{Data and estimation}

Our empirical analysis uses daily zero-coupon yield data, January 2, 1995 to September 30, 2013, obtained from Bloomberg. The yields have maturities of three and six months, one

\footnotetext{
${ }^{26}$ Duffee argues that imposing the no-arbitrage restrictions is largely inconsequential for forecasting.
} 
through ten years, 15 years, and 20 years. Our DTSM estimation sample ends in October 2008 , in order to allow us to evaluate the effects of LSAPs in a truly out-of-sample fashion. ${ }^{27}$

As in all studies that use yield data after the Great Inflation, the length of the data sample is relatively short. The requirement of a common sample period further restricts our sample and exacerbates the small-sample problem. It is therefore particularly important to address the statistical issues arising from the small sample size.

We estimate all models by numerically maximizing the likelihood function under the restriction that the largest eigenvalue of $\Phi$ does not exceed one, to prevent explosive VAR dynamics.

\subsection{Summary statistics}

Table 3 reports summary statistics for the estimated models. The first column shows the number of parameters, and the next three columns show in-sample measures of model fit, the root-mean-square pricing error (RMSE), the log-likelihood function, and the BIC. The models fit yields well, with RMSEs between 6.7 and 9.1 basis points. The similarity of the RMSEs across specifications for each country implies that the parameter restrictions barely affect cross-sectional fit. The BIC, which rewards parsimony, is always smallest for one of the restricted models. ${ }^{28}$ However, the differences in the log-likelihoods and in the BIC across models are quite small, and there is no overwhelming evidence in favor of any particular model specification.

The estimated persistence of the risk factors is crucial because it determines the variability of expected future short rates. Columns (5) and (6) of Table 3 show the largest eigenvalue of the mean-reversion matrix of the VAR and a more intuitive measure of persistence, the impulse

\footnotetext{
${ }^{27}$ DTSMs can be extended to include macroeconomic information, as in Ang and Piazzesi (2003), or survey data, as in Kim and Orphanides (2012). However, such data are available only at lower frequencies (monthly or quarterly). Filtering such survey data to higher frequency would necessarily preclude substantial day-to-day changes, limiting their usefulness in this event study.

${ }^{28} \mathrm{It}$ is not the case that the BIC is always smallest for the R-BIC model, because this model focuses only zero restrictions on risk sensitivities.
} 
response of the level factor to a level shock at a horizon of five years. The estimated persistence differs substantially between specifications. ${ }^{29}$ The OLS model displays very low persistencethe shocks typically die out almost entirely over the course of five years. The BC model always implies higher persistence than the OLS model. The RW and UR models naturally imply the most persistent dynamics, as they impose a maximal eigenvalue equal to one. The models with restricted risk prices typically, though not always, imply higher persistence than does OLS. This is what one would expect in light of the arguments in Joslin et al. (2012) and Bauer (2011) that using cross-sectional information to pin down the VAR parameters increases estimated persistence. ${ }^{30}$

Columns (7) through (10) of the table show the standard deviations of daily changes in the actual ten-year yield, its expectations component, and the corresponding term premium, as well as the correlation between changes in expectations and the term premium. The models imply very different variability and correlations of expectations and term premium components. This shows that these models have very different economic implications when it comes to interpreting movements in long-term yields. In all countries, the OLS estimates imply low volatility for short-rate expectations, due to the high degree of estimated mean reversion of the VAR, and very high variability for the term premium. This parallels the observation of Kim and Orphanides (2012) and others that unrestricted DTSM estimates can often lead to overly stable short-rate expectations and excessive term premium volatility. Consequently, we are cautious about accepting the OLS results. The BC, RW and UR models typically imply the most variable short-rate expectations, due to the higher persistence. ${ }^{31}$

In summary, the models fit the data similarly well but differ substantially in their implications for persistence and risk premia. This reflects a general problem in the DTSM literature:

\footnotetext{
${ }^{29}$ Although the eigenvalues appear very similar, even small differences can mean a big difference in long-run behavior, due to the exponentiation of the mean-reversion matrix in the calculation of long-term forecasts.

${ }^{30}$ The German R-BIC model and the Australian R-CP model imply values for the IRF that exceeds one at the five-year horizon. While the estimated VAR is highly persistent, it is, however, stationary, and the IRF declines (slowly) toward zero in both cases.

${ }^{31}$ For Canada and Germany, the R-BIC model implies constant term premia, because the BIC favors the specification with a zero risk sensitivity matrix.
} 
Small, statistically plausible changes in specifications can imply big differences in economic behavior (Kim and Orphanides, 2012). ${ }^{32}$ We will see below that the models also have very different implications for the decomposition of yield changes around LSAP events into changes in expectations and changes in term premia.

\subsection{Out-of-sample forecasting}

How should we weight the results of the models in drawing inference, i.e., which model or set of models should we trust? Choosing the model with the best likelihood or BIC would be unsatisfactory for two reasons: First, differences in model fit criteria are quite small across models. Second, and more importantly, such metrics do not capture what we are interested in: the accuracy of the estimated short-rate expectations. To assess which model-implied expectations are most reliable, we evaluate the models' out-of-sample (OOS) forecasting performance. We initially estimate the models on the first half of the sample and then forecast yields out to a horizon of one year. We then expand the sample by one day and again forecast out to one year. We iterate in this fashion, re-estimating the models not every day but only after each year, to keep the computational cost manageable.

The last two columns of Table 3 show the root-mean-square forecast errors (RMSFEs), in basis points, for forecasts of the two-year yield at horizons of six and twelve months. The RW model typically does very well, and is among the best three models in all countries. This accords with the results in Duffee (2011) who found that such restricted models forecast well. Furthermore, the models with restricted risk prices perform quite well across countries, in line with the findings in Cochrane and Piazzesi (2008) and Bauer (2011) that restricting risk prices leads to more accurate physical measure expectations. Below, we present estimates of the expectations and term premium effects of LSAP announcements for all six models, but

\footnotetext{
${ }^{32}$ This problem is closely related to the observational equivalence between a very persistent stationary time series and a non-stationary time series, and to the difficulty of accurately estimating a time series model for a process that displays a very slow speed of mean reversion.
} 
we place greater confidence in models that forecast well. For each country, we identify three "preferred" models that forecast best at the one year horizon-other forecast horizons would provide similar rankings - and focus on these models in our decomposition of LSAP effects.

\section{The impact of LSAPs on international yields}

This section presents and discusses the evidence about the importance of the signaling and portfolio balance channels for the international effects of the Fed's LSAP program.

\subsection{Model-free results}

We first assess the effects of our selected Fed LSAP announcements on international interest rates, as in Neely (2013). These model-free estimates suggest some tentative conclusions about the importance of the LSAP channels.

The first three columns of Table 4 show the changes in the two-year overnight indexed swap (OIS) rate and in the two-year and ten-year government bond yields on the key event days. The row labeled "volatility" displays the standard deviation of daily changes to put the event changes in perspective. ${ }^{33}$ The last three rows show the cumulative changes over all events in each of the three purchase programs. Asterisks in the table denote statistically significant changes, i.e., unusual changes compared to the distribution of daily changes. ${ }^{34}$

The third column of Table 4 shows that the biggest declines in long-term interest rates occurred for United States bonds for all three episodes. The ten-year yield changes are economically and statistically significant on several individual days and in total for QE1. ${ }^{35}$ For

\footnotetext{
${ }^{33}$ For the OIS rates, which are obtained from Bloomberg, the available sample is shorter than for zero-coupon yields. The sample starts in December 1999 for Germany, in December 2001 for the U.S., in June 2003 for Australia, in December 2005 for Japan, and in October 2007 for Canada.

${ }^{34}$ To obtain significance levels, we regress daily changes on dummies for LSAP announcements. The significance level of the total/cumulative effect is obtained from an $F$-test of the restriction that the coefficients sum to zero.

${ }^{35}$ We caution the reader not to interpret the total yield changes as estimates of the total effects of the three programs because we cannot claim to study all events that changed expectations about the programs. For similar reasons, one cannot use these numbers to conclude that QE1 was more effective than QE2 or QE3.
} 
QE1, the cumulative declines in long-term yields were also very sizable in Canada, Germany, and Australia (45-66 basis points), and the declines were statistically significant. The smallest QE1 declines took place in Japan, where the ten-year yield decreased only 15 basis points over the four QE1 events, and the change was not significant. The results indicate that the announcements associated with the Fed's first LSAP program had large international effects on foreign yields. They are generally consistent with those in Neely (2013), which is not surprising, given the similarities in methods. The domestic and international effects on interest rates were smaller for the subsequent LSAP programs, QE2 and QE3, and not statistically significant. ${ }^{36}$ The effects were smaller for these programs likely because further asset purchases were already anticipated by market participants at the time of the official announcements. The remainder of our paper focuses on how much signaling and portfolio balance effects contributed to these yield changes.

Changes in short-term yields can suggest the importance of shifts in the near-term expected short rate, because term premia at such maturities are typically small and stable (Gagnon et al., 2011; Hanson and Stein, 2012). Therefore, large declines in two-year yields would suggest a significant role for lower expected short-term rates in explaining the decrease in long-term rates, i.e., for the signaling channel. In addition, OIS rates, which reflect the risk-adjusted expectation of the average policy rate over the term of the contract, provide an alternative market-based measure of policy expectations (Joyce et al., 2011; Woodford, 2012). For Germany, as a euro zone member, changes in OIS rates are likely a more reliable indicator of the expected path of the European Central Bank's policy rate than movements in its two-year yield.

The first two columns of Table 4 show that two-year yields and OIS rates generally declined for all three LSAP programs in the United States, Canada, Germany, and Australia. ${ }^{37}$ The

\footnotetext{
${ }^{36}$ German long rates rose 16 bp on September 13, 2012, likely because of events related to the European Monetary Union, such as an ECB decision to renew bond buying and a German court ruling in favor of the European Stability Mechanism.

${ }^{37}$ German 2-year yields did not change over the sum of the QE3 events.
} 
decreases in Canadian two-year rates were comparable to those in the United States. The decreases in the German two-year OIS rate were also large for QE1 and QE2. For Australia, the declines in two-year rates were sizable as well.

In Japan, however, the OIS rate declined by less than half as much as the ten-year yield for the QE1 events and it did not decline at all for the QE2 and QE3 events. The very low initial level of short rates in Japan likely accounts for such a small decline in short rates and it suggests substantially weaker signaling effects for Japan than for the other countries.

These results indicate that the LSAP announcements lowered short-rate expectations substantially in the U.S., Canada, Germany, and Australia. However, such a model-free analysis can only provide qualitative conclusions. To quantify the importance of changes in expectations for changes in long-term yields, we need to use a model-based analysis.

\subsection{Model-based decompositions}

The last six columns of Table 4 report the changes in the expectations component of the ten-year yield for each of the LSAP announcements, the standard deviations of daily changes in the short-rate expectations implied by each DTSM and the cumulative change over the set of events for QE1, QE2 and QE3. Figures 1 to 3 illustrate these total changes: The first bar in each panel shows the total change in the ten-year yield, and the following six bars show the total changes in the expectations component of the ten-year yield, according to each model. The height of these six bars estimates the importance of changing short-rate expectations for LSAP effects, and the difference between the height of the first bar and each of the other six bars estimates the residual changes due to the term premium. For example, the first panel of Figure 1 shows that the total effect of the QE1 announcements considered here on U.S. 10-year yields was a decline of about 123 basis points. The RW model attributes about 74 basis points of this decline to the reduction in expected risk neutral rates and therefore $(123-74=) 49$ 
basis points to the reduction in the term premium. ${ }^{38}$

Table 5 summarizes the results for each country and LSAP program. It focuses on the implications of the three preferred models for each country - those with the best OOS forecasting performance - which are listed in the second column. The table reproduces the cumulative changes in two-year and ten-year yields, and reports the average, minimum, and maximum cumulative changes in short-rate expectations over the three preferred models. In the last column, we show the percentage share of the ten-year yield change that is explained by changes in the expectations component. For example, the first row of Table 5 shows that the three preferred models for the US are the RW, R-BIC and R-CP. During the selected QE1 event windows, the cumulative declines in U.S. two- and ten-year yields were 42.7 and 122.8 basis points. On average, the three preferred models attribute 78.5 basis points of the decline in the 10-year yield to the expectations component and this accounts for $64 \%$ of the total change. The remaining $36 \%$ would be attributed to changes in the term premium.

Figures 1 to 3 illustrate the sensitivity of the decomposition of long-term yields to the model choice. Generally, the estimated magnitudes of changes in expectations correspond to the degree of interest rate persistence of the model. The wide range of estimates across models reflects the fact that the degree of persistence and therefore movements in expectations and term premia are hard to estimate. While there is sizable statistical uncertainty around our estimates, some common patterns emerge, which we now discuss.

\subsubsection{U.S. and Canada: strong signaling effects}

For the U.S., the last column of Table 5 shows that the preferred models imply that the expectations component contributes between $45 \%$ and $90 \%$ to the total fall in the long rate over the three QE episodes. The averages over these models are high and remarkably stable over the three episodes, at about $66 \%$. The strong signaling effects for the U.S. are consistent

\footnotetext{
${ }^{38}$ Again, we caution the reader that because we cannot claim to isolate all events associated with changes in expectations about the programs, we cannot interpret the sums of yield changes for the event sets as estimating the total impact of each program.
} 
with Bauer and Rudebusch (2013b) and Christensen and Rudebusch (2012). These studies estimate that expectations contributed $50 \%$ or more of the total effects of QE1. This is in line with our results, and we show that similar conclusions hold for QE2 and QE3.

For Canada, the estimated range over our preferred models is also very high, from $68 \%$ to 98\%. The averages over these models are around $80 \%$ for all three LSAP episodes. The finding that U.S. LSAP announcements likely changed expected future Canadian short rates quite significantly is consistent with the results in Section 3.1 that showed that U.S. monetary policy surprises explain more variation in Canadian yields than those of any other non-U.S. country in our sample. The influence of unconventional U.S. monetary policy on Canadian yields appears to extend the finding of a strong U.S. conventional signaling effect.

The large contribution of changes in expectations to yield declines evince a strong signaling channel for the U.S. and Canada during all three LSAP episodes. These model-based findings are consistent with the model-free evidence presented above. Portfolio balance effects appear to be somewhat less important than signaling for these countries. Small international portfolio balance effects on Canadian yields are in line with the more modest comovement of Canadian and U.S. excess bond returns documented in Section 3.2.

\subsubsection{Germany and Australia: moderate but non-negligible signaling effects}

For Germany, the preferred models imply a range for the contribution of expectations to declines in German yields on QE1 and QE2 dates from about 35\% to 100\%, with averages of 56\% and $79 \%$. The wide estimated ranges, and the fact that for some models estimated short-rate expectations actually slightly increased around LSAP announcements (see Figure 1), indicate a large degree of model uncertainty for Germany. ${ }^{39}$ The already very low German yield curve and model-implied expected future short rates (prior to the policy announcements) probably

\footnotetext{
${ }^{39}$ For the QE3 period, as discussed previously, German long rates and expected short rates actually rose around the key announcements, likely due to news about ECB bond buying that reduced spreads with peripheral countries. Thus, one cannot estimate a signaling or portfolio balance effect for these episodes, due to the presence of euro area news.
} 
can explain the more limited changes in expectations and the seemingly counterintuitive finding that estimated short-rate expectations increased for some models on QE1 dates. Overall, international signaling effects on German yields appeared to be more moderate but still significant. The signaling effects to Germany appear to be smaller than those to Canada, but still sizable. This is consistent with the moderate but significant link between conventional U.S. monetary policy surprises and German yields from Section 3.1. Portfolio balance effects likely played a relatively more substantial role in Germany than in the U.S. and Canada. This finding is consistent with the strong comovement between U.S. and German excess bond returns that we documented in Section 3.2.

For Australia, model uncertainty is particularly high. The estimated ranges for the preferred models extend from about $0 \%$ to $100 \%$ for all three episodes. In addition, the OOS forecasting performances were rather similar across models, suggesting that there is no strong reason to prefer some models over others. Judging by the average estimated contributions of expectations across the preferred models - 55\%, 35\% and 56\% for QE1, QE2 and QE3, respectively - the preferred model imply substantial changes in short-rate expectations, which supports the view that signaling produced a large part of LSAP effects on Australian yields. This is consistent with our findings in Section 3.1 and those of Craine and Martin (2008), which showed a significant but quantitatively moderate link between conventional U.S. monetary policy and Australian yields. The larger model uncertainty and lower estimates for the importance of expectation changes suggest that in Australia, as in Germany, portfolio balance effects likely played a relatively more important role than in the U.S. and Canada. This is consistent with the high comovement between U.S. and Australian bond returns (Section 3.2).

In sum, the evidence indicates somewhat weaker but still very sizeable signaling effects for Germany and Australia. At the same time, portfolio balance effects likely played a more important role than they did for the U.S. and Canada, consistent with international bond return comovements. 


\subsubsection{Japan: negligible signaling and weak portfolio balance effects}

For Japan, the results are clear: Expected short-term interest rates barely moved in response to the unconventional policy announcements, i.e., signaling effects appear to have been marginal. This was to be expected, given the weak impact of U.S. monetary policy surprises on Japanese yields (Section 3.1) and the very low initial level of Japanese short rates, short-rate expectations and yields at the time of the U.S. policy announcements.

Decreasing term premia can explain the modest observed decreases in yields, consistent with a modest but non-negligible portfolio balance channel. This is consistent with our prediction that the portfolio balance channel would likely be very modest for the case of Japan, based on the low comovement between Japanese and U.S. excess bond returns. The absence of a signaling channel and the modest effect of the portfolio balance channel explain the very small overall response of Japanese yields to the Fed's LSAP announcements.

\section{Conclusion}

Previous research has found that the Federal Reserve's LSAP program strongly influenced international bond yields (see Neely, 2013). This paper investigates the relative importance of signaling and portfolio balance channels for the international bond yield effects of Fed unconventional policy announcements in 2008-2009. We draw conclusions both about methodology and the importance of signaling and portfolio balance channels.

Our methodology demonstrates that the estimated changes in short-rate expectations and term premia are quite sensitive to model specification. We recommend that other researchers studying the term structure of interest rates also consider this model uncertainty, lest they have too much confidence in their (possibly misleading) results. In particular, the conventional (OLS) DTSM estimates would have led to very different conclusions than the ones we draw from a broader set of models. Models that impose high persistence in short rates, which 
naturally imply larger changes in short-rate expectations and stronger signaling effects, tend to forecast well and appear to be useful, although these are not widely used as of yet. Their good out-of-sample forecasting performance leads us to place more weight on inference from these models. Studying methods to increase statistical confidence-by imposing more parameter restrictions, using more data, and taking advantage of structural dependencies that are wellunderstood - should clearly be a high priority for the yield curve literature.

Our empirical results show that both the signaling channel and the portfolio balance channel likely made substantial contributions to the decline in yields in most countries. For the U.S. and Canada, the evidence for pronounced signaling effects is strongest, and the results are consistent across all three LSAP programs considered. For Germany and Australia, there is also evidence for signaling effects, however with slightly more uncertainty surrounding our estimates. For Japan, the signaling effects are negligible, in line with Japanese rates already being very depressed at short and medium maturities. Our evidence indicates that portfolio balance effects were likely relatively more important for Australia and Germany than for

the U.S. and Canada and that portfolio balance effects were modest for Japan. Overall, we find that the evidence on the relative importance of the international effects of the Fed's LSAP programs on foreign yields are largely consistent with past sensitivity to conventional U.S. monetary policy surprises and with the covariance of foreign and U.S. bond returns.

\section{Acknowledgements}

The authors thank Jean-Yves Gnabo, Carlo Rosa, and Raf Wouters for their helpful comments, Brett Fawley, Kevin Cook and Sean Grover for excellent research assistance, and participants at the following conferences for their suggestions: the Federal Reserve System Committee Meetings on Business and Financial Analysis, the INFINITI 2013 Conference, the Missouri Economics Conference, and the FUNDP Namur, CeReFiM Workshop on Unconventional Central Bank Policy during the Global Financial Crises. All remaining errors are ours. 


\section{References}

Ammer, J., Vega, C., Wongswan, J., September 2010. International transmission of us monetary policy shocks: evidence from stock prices. Journal of Money, Credit and Banking 42 (s1), 179-198.

Andersen, T. G., Bollerslev, T., Diebold, F. X., Vega, C., March 2003. Micro effects of macro announcements: Real-time price discovery in foreign exchange. American Economic Review $93(1), 38-62$.

Ang, A., Piazzesi, M., May 2003. A no-arbitrage vector autoregression of term structure dynamics with macroeconomic and latent variables. Journal of Monetary Economics 50 (4), $745-787$.

Bauer, M. D., November 2011. Bayesian estimation of dynamic term structure models under restrictions on risk pricing. Working Paper 2011-03, Federal Reserve Bank of San Francisco.

Bauer, M. D., Rudebusch, G. D., 2013a. Monetary policy expectations at the zero lower bound. Working Paper 18, Federal Reserve Bank of San Francisco.

Bauer, M. D., Rudebusch, G. D., April 2013b. The signaling channel for federal reserve bond purchases. Working paper 2011-21, Federal Reserve Bank of San Francisco.

Bauer, M. D., Rudebusch, G. D., Wu, J. C., July 2012. Correcting estimation bias in dynamic term structure models. Journal of Business and Economic Statistics 30 (3), 454-467.

Christensen, J. H. E., Rudebusch, G. D., November 2012. The response of interest rates to us and uk quantitative easing. Economic Journal 122 (564), F385-F414.

Cochrane, J. H., Piazzesi, M., March 2005. Bond risk premia. American Economic Review 95 (1), 138-160.

Cochrane, J. H., Piazzesi, M., 2008. Decomposing the yield curve. unpublished manuscript. 
Craine, R., Martin, V. L., May 2008. International monetary policy surprise spillovers. Journal of International Economics 75, 180-196.

D'Amico, S., English, W., Lopez-Salido, D., Nelson, E., November 2012. The federal reserve's large-scale asset purchase programmes: Rationale and effects. Economic Journal 122 (564), F415-F446.

D’Amico, S., King, T. B., May 2013. Flow and stock effects of large-scale treasury purchases: Evidence on the importance of local supply. Journal of Financial Economics 108 (2), 425448.

Duffee, G. R., 2011. Forecasting with the term structure: the role of no-arbitrage. Working Paper January, Johns Hopkins University.

Eggertson, G., March 2006. The deflation bias and committing to being irresponsible. Journal of Money, Credit, and Banking 38 (2), 283-321.

Ehrmann, M., Fratzscher, M., December 2009. Global financial transmission of monetary policy shocks*. Oxford Bulletin of Economics and Statistics 71 (6), 739-759.

Faust, J., Rogers, J. H., Wang, S.-Y. B., Wright, J. H., May 2007. The high-frequency response of exchange rates and interest rates to macroeconomic announcements. Journal of Monetary Economics 54 (4), 1051-1068.

Fawley, B., Neely, C. J., January/February 2013. Four stories of quantitative easing. Federal Reserve Bank of St. Louis Review 95 (1), 51-88.

Gagnon, J., Raskin, M., Remache, J., Sack, B., March 2011. The financial market effects of the federal reserve's large-scale asset purchases. International Journal of Central Banking $7(1), 3-43$. 
Glick, R., Leduc, S., 2012. Central bank announcements of asset purchases and the impact on global financial and commodity markets. Journal of International Money and Finance 31 (8), 2078-2101.

Gürkaynak, R. S., Sack, B. P., Swanson, E. T., May 2005. Do actions speak louder than words? the response of asset prices to monetary policy actions and statements. International Journal of Central Banking 1 (1), 55-93.

Hamilton, J. D., Wu, J. C., February 2012. The effectiveness of alternative monetary policy tools in a zero lower bound environment. Journal of Money, Credit and Banking 44 (s1), 3-46.

Hanson, S. G., Stein, J. C., July 2012. Monetary policy and long-term real rates. Finance and Economics Discussion Series 2012-46, Federal Reserve Board of Governors.

Hausman, J., Wongswan, J., April 2011. Global asset prices and fomc announcements. Journal of International Money and Finance 30 (3), 547-571.

Joslin, S., Priebsch, M., Singleton, K. J., October 2012. Risk premiums in dynamic term structure models with unspanned macro risks. working paper.

Joslin, S., Singleton, K. J., Zhu, H., March 2011. A new perspective on gaussian dynamic term structure models. Review of Financial Studies 24 (3), 926-970.

Joyce, M., Lasaosa, A., Stevens, I., Tong, M., September 2011. The financial market impact of quantitative easing in the united kingdom. International Journal of Central Banking 7 (3), 113-161.

Kilian, L., May 1998. Small-sample confidence intervals for impulse response functions. Review of Economics and Statistics 80 (2), 218-230. 
Kim, D. H., Orphanides, A., Feb. 2012. Term structure estimation with survey data on interest rate forecasts. Journal of Financial and Quantitative Analysis 47 (1), 241-272.

Kim, D. H., Singleton, K. J., September 2012. Term structure models and the zero bound: An empirical investifation of japanese yields. Journal of Econometrics 170 (1), 32-49.

Krishnamurthy, A., Vissing-Jorgensen, A., Fall 2011. The effects of quantitative easing on interest rates: Channels and implications for policy. Brookings Papers on Economic Activity, $215-265$.

Kuttner, K. N., June 2001. Monetary policy surprises and interest rates: Evidence from the fed funds futures market. Journal of Monetary Economics 47 (3), 523-544.

Li, C., Wei, M., March 2013. Term structure modelling with supply factors and the federal reserve's large scale asset purchase programs. International Journal of Central Banking 9 (1), $3-39$.

Neely, C. J., August 2013. Unconventional monetary policy had large international effects. Working Paper Series 2010-018E, Federal Reserve Bank of St. Louis.

Rosa, C., May 2012. How "unconventional" are large-scale asset purchases? the impact of monetary policy on asset prices. Staff Report No. 560, Federal Reserve Bank of New York.

Woodford, M., September 2012. Methods of policy accommodation at the interest-rate lower bound. paper presented at the 2012 jackson hole conference, Federal Reserve Bank of Kansas City.

Wright, J. H., 2012. What does monetary policy do to long-term interest rates at the zero lower bound?*. The Economic Journal 122 (564), F447-F466. 


\section{A Affine bond pricing and JSZ normalization}

The VAR for the risk factors under the real-world probability measure is given in the text in equation (2). The short-term interest rate, $r_{t}$, is an affine function of the risk factors,

$$
r_{t}=\delta_{0}+\delta_{1}^{\prime} X_{t}
$$

where $\delta_{0}$ is a scalar and $\delta_{1}$ is an $N$-vector. The stochastic discount factor (SDF) is of the exponentially-affine form

$$
-\log \left(M_{t+1}\right)=r_{t}+\frac{1}{2} \lambda_{t}^{\prime} \lambda_{t}+\lambda_{t}^{\prime} \varepsilon_{t+1}
$$

where the risk prices are affine in the risk factors,

$$
\Sigma \lambda_{t}=\lambda_{0}+\lambda_{1} X_{t}
$$

for $N$-vector $\lambda_{0}$ and $N \times N$ matrix $\lambda_{1}$. Under these assumptions, $X_{t}$ also follows a first-order Gaussian VAR under the pricing measure $\mathbb{Q}$,

$$
X_{t+1}=\mu^{\mathrm{Q}}+\Phi^{\mathrm{Q}} X_{t}+\Sigma \varepsilon_{t+1}^{\mathrm{Q}}
$$

The risk price parameters, $\lambda_{0}$ and $\lambda_{1}$, determine how the parameters under $\mathbb{P}$ and $\mathbb{Q}$ are related. Specifically, we have $\mu^{\mathbb{Q}}=\mu-\lambda_{0}$ and $\Phi^{\mathbb{Q}}=\Phi-\lambda_{1}$. Bond prices are exponentially affine functions of the pricing factors:

$$
P_{t}^{m}=e^{\mathcal{A}_{m}+\mathcal{B}_{m} X_{t}}
$$

and the loadings $\mathcal{A}_{m}=\mathcal{A}_{m}\left(\mu^{\mathbb{Q}}, \Phi^{\mathbb{Q}}, \delta_{0}, \delta_{1}, \Sigma\right)$ and $\mathcal{B}_{m}=\mathcal{B}_{m}\left(\Phi^{\mathbb{Q}}, \delta_{1}\right)$ follow the recursions

$$
\begin{aligned}
\mathcal{A}_{m+1} & =\mathcal{A}_{m}+\left(\mu^{\mathbb{Q}}\right)^{\prime} \mathcal{B}_{m}+\frac{1}{2} \mathcal{B}_{m}^{\prime} \Sigma \Sigma^{\prime} \mathcal{B}_{m}-\delta_{0} \\
\mathcal{B}_{m+1} & =\left(\Phi^{\mathbb{Q}}\right)^{\prime} \mathcal{B}_{m}-\delta_{1}
\end{aligned}
$$

with starting values $\mathcal{A}_{0}=0$ and $\mathcal{B}_{0}=0$. Model-implied yields are determined by $y_{t}^{m}=$ $-m^{-1} \log P_{t}^{m}=A_{m}+B_{m} X_{t}$, with $A_{m}=-m^{-1} \mathcal{A}_{m}$ and $B_{m}=-m^{-1} \mathcal{B}_{m}$.

Denote by $\hat{Y}_{t}$ the vector of observed yields on day $t$. The number of observed yield maturities is $J$. We take the risk factors $X_{t}$ to be the first $N=3$ principal components of observed yields. That is, if $W$ denotes the $N \times J$ matrix with rows corresponding to the first three eigenvectors of the covariance matrix of $\hat{Y}_{t}$, we have $X_{t}=W \hat{Y}_{t}$. As is common in the literature, we specify observed yields to include i.i.d. measurement errors, $\hat{Y}_{t}=Y_{t}+e_{t}$, which we take to have equal variance across yields. ${ }^{40}$

We parameterize the model using the canonical form of Joslin et al. (2011). Thus, the free parameters of the model are $r_{\infty}^{\mathrm{Q}}=E^{\mathrm{Q}}\left(r_{t}\right)$, the risk-neutral long-run mean of the short rate,

\footnotetext{
${ }^{40}$ Note that because $N$ linear combinations of yields are priced exactly, there are effectively only $J-N$ independent measurement errors.
} 
$\lambda^{\mathbb{Q}}$, the eigenvalues of $\Phi^{\mathbb{Q}}$, and the VAR parameters $\mu, \Phi$, and $\Sigma{ }^{41}$

\footnotetext{
${ }^{41}$ To see how $\mu^{\mathbb{Q}}, \Phi^{\mathbb{Q}}, \delta_{0}$, and $\delta_{1}$ are calculated from $\left(W, \lambda^{\mathbb{Q}}, r_{\infty}^{\mathbb{Q}}, \Sigma\right)$ refer to Proposition 2 in Joslin et al. (2011).
} 
Table 1: LSAP announcements

\begin{tabular}{|c|c|c|c|c|c|}
\hline Date & Program & Event & Time & Description & Other significant news \\
\hline $11 / 25 / 2008$ & QE1 & $\begin{array}{l}\text { initial LSAP } \\
\text { announcement }\end{array}$ & $8: 15 \mathrm{a}$ & $\begin{array}{l}\text { Federal Reserve announces purchases of up to } \\
\$ 100 \text { billion in agency debt and up to } \$ 500 \\
\text { billion in agency MBS. }\end{array}$ & $\begin{array}{l}\text { FOMC minutes released on November } \\
24 .\end{array}$ \\
\hline $12 / 1 / 2008$ & QE1 & Chairman's speech & $1: 40 p$ & $\begin{array}{l}\text { Chairman Bernanke states that the Federal } \\
\text { Reserve "could purchase longer-term Treasury } \\
\text { securities [...] in substantial quantities." }\end{array}$ & $\begin{array}{l}\text { Construction spending and ISM an- } \\
\text { nouncements come in weaker than ex- } \\
\text { pected. NBER dating committee offi- } \\
\text { cially declares a recession. }\end{array}$ \\
\hline $12 / 16 / 2008$ & QE1 & FOMC statement & $2: 15 \mathrm{p}$ & $\begin{array}{l}\text { Statement indicates that the FOMC is con- } \\
\text { sidering expanding purchases of agency secu- } \\
\text { rities and initiating purchases of Treasury se- } \\
\text { curities. }\end{array}$ & $\begin{array}{l}\text { FOMC lowers the target for the Fed- } \\
\text { eral funds rate from } 1 \text { percent to a } 0-25 \\
\text { bp range, and expects "exceptionally } \\
\text { low levels of the federal funds rate for } \\
\text { some time." }\end{array}$ \\
\hline $03 / 18 / 2009$ & QE1 & FOMC statement & $2: 15 \mathrm{p}$ & $\begin{array}{l}\text { Statement announces purchases "up to an ad- } \\
\text { ditional } \$ 750 \text { billion of agency [MBS]," } \$ 100 \\
\text { billion in agency debt, and } \$ 300 \text { billion in } \\
\text { Treasury securities. }\end{array}$ & $\begin{array}{l}\text { FOMC expects "exceptionally low lev- } \\
\text { els of the federal funds rate for an ex- } \\
\text { tended period." }\end{array}$ \\
\hline $08 / 10 / 2010$ & QE2 & FOMC statement & $2: 15 p$ & $\begin{array}{l}\text { Balance Sheet Maintained: Fed will reinvest } \\
\text { principal payments from LSAP purchases in } \\
\text { Treasuries. }\end{array}$ & $\begin{array}{l}\text { Bank of Japan released a monetary } \\
\text { policy statement. }\end{array}$ \\
\hline $09 / 21 / 2010$ & QE2 & FOMC statement & $2: 15 \mathrm{p}$ & $\begin{array}{l}\text { Statement projects that inflation "is likely to } \\
\text { remain subdued for some time before rising } \\
\text { to levels the Committee considers consistent } \\
\text { with its mandate." }\end{array}$ & \\
\hline $11 / 03 / 2010$ & QE2 & FOMC statement & $2: 15 \mathrm{p}$ & $\begin{array}{l}\text { Statement announces purchases of } \$ 600 \text { bil- } \\
\text { lion in Treasury securities }\end{array}$ & $\begin{array}{l}\text { ECB intervenes to stem peripheral } \\
\text { debt problems. }\end{array}$ \\
\hline $08 / 22 / 2012$ & QE3 & FOMC minutes & $2: 00 p$ & $\begin{array}{l}\text { FOMC members "judged that additional } \\
\text { monetary accomodation would likely be war- } \\
\text { ranted fairly soon." }\end{array}$ & $\begin{array}{l}\text { Sales of existing US homes lower than } \\
\text { consensus expectations. }\end{array}$ \\
\hline $09 / 13 / 2012$ & QE3 & FOMC statement & $2: 15 \mathrm{p}$ & $\begin{array}{l}\text { Fed will purchase } \$ 40 \text { billion of MBS per } \\
\text { month as long as "the outlook for the labor } \\
\text { market does not improve substantially [...] in } \\
\text { the context of price stability." }\end{array}$ & $\begin{array}{l}\text { Initial US jobless claims were slightly } \\
\text { higher than expected. }\end{array}$ \\
\hline
\end{tabular}

Notes: The table describes the 9 events associated with asset purchase programs that are studied in this paper. The columns denote the date of the announcement, the nature of the event, the time of the event (EST), a brief description of the event and a brief description of other possibly significant news events in a 3 -day event window from $t-1$ through $t+1$. 
Table 2: Conventional U.S. monetary policy and foreign interest rates

\begin{tabular}{ll|rrrrr}
\hline \hline Yield & & U.S. & Canada & Germany & Australia & Japan \\
\hline three-month & Target & .57 & .22 & .08 & -.01 & .01 \\
& & $(11.69)$ & $(4.68)$ & $(2.50)$ & $(.26)$ & $(.44)$ \\
& Path & .03 & .06 & .02 & .05 & .01 \\
& & $(2.04)$ & $(4.96)$ & $(2.54)$ & $(3.56)$ & $(.94)$ \\
& $R^{2}$ & $50.9 \%$ & $25.5 \%$ & $8.6 \%$ & $8.6 \%$ & $.8 \%$ \\
\hline two-year & Target & .40 & .16 & .14 & .14 & .03 \\
& & $(8.06)$ & $(3.55)$ & $(2.99)$ & $(2.49)$ & $(1.16)$ \\
& Path & .18 & .09 & .06 & .07 & .02 \\
& & $(13.81)$ & $(7.67)$ & $(4.54)$ & $(4.79)$ & $(2.72)$ \\
& $R^{2}$ & $65.3 \%$ & $34.5 \%$ & $17.9 \%$ & $17.7 \%$ & $6.1 \%$ \\
\hline five-year & Target & .28 & .02 & .08 & .06 & .02 \\
& & $(4.31)$ & $(.49)$ & $(1.61)$ & $(.92)$ & $(.63)$ \\
& Path & .19 & .09 & .07 & .09 & .03 \\
& & $(11.30)$ & $(7.52)$ & $(5.50)$ & $(5.17)$ & $(2.86)$ \\
& $R^{2}$ & $51.9 \%$ & $29.5 \%$ & $19.5 \%$ & $16.9 \%$ & $5.9 \%$ \\
\hline ten-year & Target & .14 & -.07 & .00 & -.09 & -.02 \\
& & $(1.98)$ & $(1.47)$ & $(.11)$ & $(1.38)$ & $(.44)$ \\
& Path & .16 & .08 & .06 & .10 & .03 \\
& & $(8.75)$ & $(6.58)$ & $(4.86)$ & $(5.45)$ & $(2.73)$ \\
& $R^{2}$ & $37.2 \%$ & $25.0 \%$ & $14.8 \%$ & $18.8 \%$ & $5.3 \%$ \\
\hline \hline
\end{tabular}

Notes: The table shows results for regressions of foreign yield changes on U.S. monetary policy surprises as defined by Gürkaynak et al. (2005). The number of observations is 139, corresponding to FOMC announcements between February 1, 1995, and March 15, 2011. Numbers in parentheses indicate t-statistics. 
Table 3: Model summary statistics

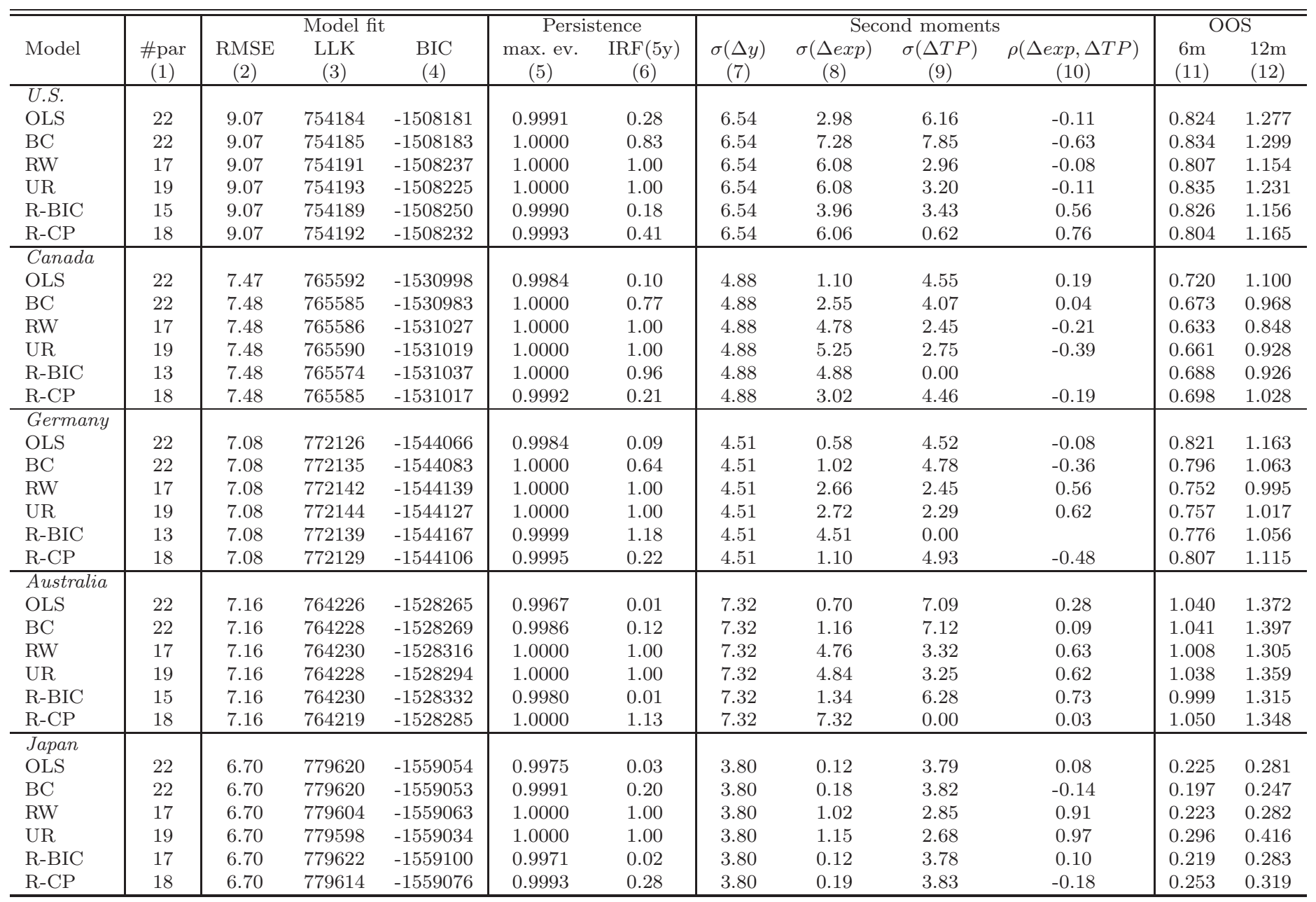

Notes: The first column shows the number of unrestricted parameters in the model (not counting measurement error variances). Columns (2) to (4) show measures of model fit, namely the root-mean-square pricing error (RMSE) in basis points, the value of the log-likelihood function (LLK), and the Bayesian Information Criterion (BIC). Column (5) shows the largest eigenvalue of $\Phi$, and column (6) shows the value of the impulse response function (IRF) of the level factor to level shocks at a horizon of five years. For the ten-year yield, columns (7) to (9) show the standard deviation of daily changes in the fitted yield $(\sigma(\Delta y))$, the expectations component $(\sigma(\Delta$ exp $)$ ), and the term premium $(\sigma(\Delta T P))$, in basis points. Column (10) shows the correlation between changes in short-rate expectations and the term premium $(\rho(\Delta e x p, \Delta T P))$. The last two columns show the root-mean-square forecast errors (RMSFEs), in basis points, for each model's forecasts of the two-year yield at horizons of six and twelve months. 
Table 4: Effects of LSAP announcements

\begin{tabular}{|c|c|c|c|c|c|c|c|c|c|c|}
\hline \multirow[b]{2}{*}{ Date } & \multirow[b]{2}{*}{ Program } & \multirow{2}{*}{$\begin{array}{c}\text { OIS } \\
2 y\end{array}$} & \multicolumn{2}{|c|}{ Yields } & \multicolumn{6}{|c|}{ Expectations component, 10y yield } \\
\hline & & & $2 \mathrm{y}$ & $10 y$ & OLS & $\mathrm{BC}$ & RW & UR & $\mathrm{R}-\mathrm{BIC}$ & $\mathrm{R}-\mathrm{CP}$ \\
\hline \multicolumn{11}{|l|}{ U.S. } \\
\hline $2008 / 11 / 25$ & QE1 & $-13.8^{*}$ & -2.4 & $-23.1^{* *}$ & 3.8 & 8.7 & -9.4 & -8.5 & $-8.5^{*}$ & $-18.9^{* *}$ \\
\hline $2008 / 12 / 01$ & QE1 & $-12.8^{*}$ & -8.6 & $-21.6^{* *}$ & -0.9 & -2.4 & $-16.6^{* *}$ & $-15.9^{* *}$ & $-11.0^{* *}$ & $-20.9^{* *}$ \\
\hline $2008 / 12 / 16$ & QE1 & $-15.2^{* *}$ & -9.1 & $-27.6^{* *}$ & 1.7 & 3.7 & $-14.7^{*}$ & $-13.8^{*}$ & $-11.5^{* *}$ & $-23.2^{* *}$ \\
\hline $2009 / 03 / 18$ & QE1 & $-12.0^{*}$ & $-22.6^{* *}$ & $-50.5^{* *}$ & -1.5 & -4.6 & $-32.7^{* *}$ & $-31.5^{* *}$ & $-24.0^{* *}$ & $-44.2^{* *}$ \\
\hline $2010 / 08 / 10$ & QE2 & -1.2 & -1.1 & -7.5 & -1.1 & -2.8 & -4.7 & -4.7 & -4.1 & -6.3 \\
\hline 2010/09/21 & QE2 & -4.1 & -4.2 & $-14.0^{*}$ & -0.1 & -0.5 & -8.0 & -7.7 & -6.4 & -11.7 \\
\hline 2010/11/03 & QE2 & -0.7 & -1.6 & -1.2 & $-6.0^{*}$ & $-14.9^{*}$ & -2.8 & -3.8 & -3.4 & 0.5 \\
\hline 2012/08/22 & QE3 & -2.5 & -3.7 & -11.0 & 0.8 & 1.7 & -6.5 & -6.0 & -4.8 & -9.9 \\
\hline 2012/09/13 & QE3 & -1.2 & -0.7 & -3.3 & -1.4 & -3.6 & -2.8 & -2.9 & -2.3 & -2.8 \\
\hline volatility & & 5.5 & 6.2 & 6.8 & 3.0 & 7.3 & 6.1 & 6.1 & 4.0 & 6.1 \\
\hline total & QE1 & $-53.9^{* *}$ & $-42.7^{* *}$ & $-122.8^{* *}$ & 3.1 & 5.4 & $-73.5^{* *}$ & $-69.7^{* *}$ & $-55.0^{* *}$ & $-107.2^{* *}$ \\
\hline total & QE2 & -6.0 & -6.9 & -22.7 & -7.2 & -18.2 & -15.6 & -16.2 & $-13.9^{*}$ & -17.6 \\
\hline total & QE3 & -3.8 & -4.4 & -14.3 & -0.7 & -1.9 & -9.2 & -8.9 & -7.1 & -12.7 \\
\hline \multicolumn{11}{|l|}{ Canada } \\
\hline $2008 / 11 / 25$ & QE1 & -9.1 & -4.6 & $-12.4^{*}$ & 0.6 & 0.3 & -5.8 & -5.5 & $-10.5^{*}$ & 1.4 \\
\hline $2008 / 12 / 01$ & QE1 & $-14.7^{* *}$ & $-15.8^{* *}$ & $-17.0^{* *}$ & -0.5 & -2.6 & $-12.6^{* *}$ & $-13.0^{*}$ & $-17.4^{* *}$ & -1.7 \\
\hline $2008 / 12 / 16$ & QE1 & $-18.8^{* *}$ & $-15.1^{*}$ & $-13.0^{*}$ & $-2.4^{*}$ & $-5.7^{*}$ & $-14.2^{* *}$ & $-14.0^{* *}$ & $-11.1^{*}$ & -4.4 \\
\hline $2009 / 03 / 18$ & QE1 & -4.2 & -7.0 & $-23.9^{* *}$ & -0.4 & -3.0 & $-12.6^{* *}$ & $-14.1^{* *}$ & $-19.3^{* *}$ & -3.1 \\
\hline $2010 / 08 / 10$ & QE2 & -0.4 & -0.5 & -2.7 & 0.0 & -0.3 & -1.3 & -1.7 & -2.6 & -0.5 \\
\hline 2010/09/21 & QE2 & -5.8 & -5.4 & -3.4 & -0.7 & -1.9 & -3.1 & -4.0 & -3.2 & -2.5 \\
\hline 2010/11/03 & QE2 & 4.6 & 0.7 & -0.7 & -0.5 & -1.1 & -0.5 & -1.0 & 0.5 & -1.7 \\
\hline $2012 / 08 / 22$ & QE3 & -6.2 & -7.8 & -9.8 & -0.5 & -2.2 & -6.8 & -7.8 & $-9.6^{*}$ & -2.6 \\
\hline 2012/09/13 & QE3 & -1.6 & -1.6 & -2.1 & -0.2 & -0.7 & -1.6 & -1.9 & -2.0 & -0.9 \\
\hline volatility & & 5.4 & 6.1 & 5.3 & 1.1 & 2.5 & 4.8 & 5.2 & 4.9 & 3.0 \\
\hline total & QE1 & $-46.8^{* *}$ & $-42.5^{* *}$ & $-66.3^{* *}$ & -2.7 & $-11.0^{*}$ & $-45.3^{* *}$ & $-46.6^{* *}$ & $-58.3^{* *}$ & -7.7 \\
\hline total & QE2 & -1.6 & -5.2 & -6.8 & -1.2 & -3.3 & -4.8 & -6.6 & -5.3 & -4.7 \\
\hline total & QE3 & -7.9 & -9.4 & -11.9 & -0.8 & -2.9 & -8.4 & -9.8 & -11.6 & -3.5 \\
\hline \multicolumn{11}{|l|}{ Germany } \\
\hline $2008 / 11 / 25$ & QE1 & -5.3 & 5.7 & -8.2 & $2.1^{* *}$ & $4.0^{* *}$ & 0.3 & -0.4 & -8.2 & $4.5^{* *}$ \\
\hline $2008 / 12 / 01$ & QE1 & $-9.6^{*}$ & -0.9 & $-12.6^{* *}$ & $1.9^{* *}$ & $3.9^{* *}$ & -3.2 & -3.6 & $-13.0^{* *}$ & $4.5^{* *}$ \\
\hline $2008 / 12 / 16$ & QE1 & $-16.4^{* *}$ & $-16.7^{* *}$ & $-14.6^{* *}$ & $-1.5^{*}$ & -1.7 & $-10.7^{* *}$ & $-10.4^{* *}$ & $-14.0^{* *}$ & -1.4 \\
\hline $2009 / 03 / 18$ & QE1 & $-12.8^{* *}$ & -0.8 & $-18.5^{* *}$ & $1.4^{*}$ & $3.2^{* *}$ & $-5.3^{*}$ & $-6.0^{*}$ & $-16.0^{* *}$ & $3.9^{* *}$ \\
\hline 2010/08/10 & QE2 & -3.9 & -7.7 & $-10.5^{*}$ & -0.5 & -0.4 & $-7.0^{* *}$ & $-7.3^{* *}$ & $-11.9^{* *}$ & 0.0 \\
\hline $2010 / 09 / 21$ & QE2 & -1.2 & -4.0 & -7.8 & 0.4 & 1.1 & -3.0 & -3.3 & -7.6 & 1.4 \\
\hline $2010 / 11 / 03$ & QE2 & -2.3 & 2.2 & 5.8 & -1.0 & $-2.1^{*}$ & 1.7 & 1.9 & 7.0 & $-2.4^{*}$ \\
\hline $2012 / 08 / 22$ & QE3 & 0.7 & -0.0 & $-10.0^{*}$ & 0.7 & 1.6 & -2.9 & -3.4 & -8.7 & 1.9 \\
\hline 2012/09/13 & QE3 & -2.3 & -0.0 & $16.5^{* *}$ & $-1.4^{*}$ & $-3.1^{* *}$ & $5.4^{*}$ & $6.2^{*}$ & $16.4^{* *}$ & $-3.8^{* *}$ \\
\hline volatility & & 4.5 & 4.5 & 4.6 & 0.6 & 1.0 & 2.7 & 2.7 & 4.5 & 1.1 \\
\hline total & QE1 & $-44.1^{* *}$ & -12.7 & $-53.9^{* *}$ & $4.0^{* *}$ & $9.5^{* *}$ & $-18.8^{* *}$ & $-20.4^{* *}$ & $-51.3^{* *}$ & $11.5^{* *}$ \\
\hline total & QE2 & -7.4 & -9.5 & -12.5 & -1.1 & -1.4 & -8.3 & -8.7 & -12.5 & -1.0 \\
\hline total & QE3 & -1.6 & 0.0 & 6.5 & -0.7 & -1.6 & 2.4 & 2.8 & 7.7 & -1.9 \\
\hline
\end{tabular}

Continued on next page. 
Table 4 (continued): Effects of LSAP announcements

\begin{tabular}{|c|c|c|c|c|c|c|c|c|c|c|}
\hline \multirow[b]{2}{*}{ Date } & \multirow[b]{2}{*}{ Program } & \multirow{2}{*}{$\begin{array}{c}\text { OIS } \\
2 y\end{array}$} & \multicolumn{2}{|c|}{ Yields } & \multicolumn{6}{|c|}{ Expectations component, 10y yield } \\
\hline & & & $2 y$ & $10 \mathrm{y}$ & OLS & $\mathrm{BC}$ & RW & UR & R-BIC & $\mathrm{R}-\mathrm{CP}$ \\
\hline Australia & & & & & & & & & & \\
\hline $2008 / 11 / 25$ & QE1 & -6.0 & -0.5 & 6.1 & -0.0 & -0.1 & 1.9 & 2.0 & 0.4 & 3.7 \\
\hline $2008 / 12 / 01$ & QE1 & -18.1 & -7.5 & -5.3 & -0.4 & -0.5 & -4.3 & -4.3 & -1.1 & -6.4 \\
\hline $2008 / 12 / 16$ & QE1 & 0.5 & -7.0 & $-17.9^{*}$ & 0.4 & 1.1 & -7.3 & -7.2 & -1.1 & $-16.6^{*}$ \\
\hline $2009 / 03 / 18$ & QE1 & -9.0 & -14.3 & $-28.5^{* *}$ & -0.3 & 0.2 & $-14.5^{* *}$ & $-14.3^{* *}$ & $-2.9^{*}$ & $-27.5^{* *}$ \\
\hline $2010 / 08 / 10$ & QE2 & -4.7 & -6.4 & -5.7 & -0.1 & -0.1 & -3.5 & -3.7 & -0.9 & -5.9 \\
\hline $2010 / 09 / 21$ & QE2 & -0.1 & 1.3 & -5.0 & 0.8 & 1.5 & -0.3 & -0.4 & 0.5 & -4.7 \\
\hline 2010/11/03 & QE2 & -1.4 & 3.1 & -3.0 & 1.1 & 1.9 & 1.5 & 1.2 & 1.0 & -2.2 \\
\hline $2012 / 08 / 22$ & QE3 & -12.2 & -9.0 & -9.4 & -0.7 & -1.0 & -6.9 & -6.9 & -1.8 & -9.9 \\
\hline 2012/09/13 & QE3 & -3.5 & 7.5 & 5.5 & 0.7 & 1.0 & 4.8 & 4.9 & 1.5 & 5.8 \\
\hline volatility & & 9.3 & 7.4 & 8.0 & 0.7 & 1.2 & 4.8 & 4.8 & 1.3 & 7.3 \\
\hline total & QE1 & -32.6 & $-29.3^{*}$ & $-45.6^{* *}$ & -0.3 & 0.6 & $-24.2^{*}$ & $-23.9^{*}$ & -4.7 & $-46.8^{* *}$ \\
\hline total & QE2 & -6.2 & -2.0 & -13.7 & 1.8 & 3.3 & -2.3 & -2.9 & 0.6 & -12.8 \\
\hline total & QE3 & -15.7 & -1.5 & -3.9 & -0.0 & 0.0 & -2.1 & -2.0 & -0.4 & -4.1 \\
\hline Japan & & & & & & & & & & \\
\hline $2008 / 11 / 25$ & QE1 & -1.5 & 1.5 & -1.8 & 0.2 & 0.2 & -0.1 & -0.5 & 0.2 & 0.2 \\
\hline $2008 / 12 / 01$ & QE1 & -3.2 & -3.2 & -3.5 & -0.1 & -0.1 & -1.0 & -1.1 & -0.1 & -0.1 \\
\hline $2008 / 12 / 16$ & QE1 & -2.0 & $-5.7^{*}$ & -7.7 & $-0.4^{* *}$ & $-0.5^{* *}$ & $-2.1^{*}$ & -1.4 & $-0.4^{* *}$ & -0.3 \\
\hline $2009 / 03 / 18$ & QE1 & -0.0 & $-5.0^{*}$ & -2.0 & $-0.4^{* *}$ & $-0.6^{* *}$ & -1.5 & -0.7 & $-0.4^{* *}$ & $-0.5^{*}$ \\
\hline $2010 / 08 / 10$ & QE2 & -0.0 & 0.2 & -2.2 & 0.0 & 0.1 & -0.5 & -0.7 & 0.1 & 0.2 \\
\hline $2010 / 09 / 21$ & QE2 & 0.1 & -1.0 & -2.0 & -0.0 & -0.0 & -0.5 & -0.6 & -0.0 & -0.1 \\
\hline $2010 / 11 / 03$ & QE2 & -0.0 & -0.8 & -2.3 & -0.0 & 0.0 & -0.7 & -0.8 & -0.0 & 0.0 \\
\hline $2012 / 08 / 22$ & QE3 & -0.1 & -0.2 & 0.5 & -0.0 & -0.1 & 0.0 & 0.1 & -0.0 & -0.1 \\
\hline 2012/09/13 & QE3 & 0.1 & 0.6 & -1.5 & 0.1 & 0.1 & -0.3 & -0.6 & 0.1 & 0.0 \\
\hline volatility & & 2.1 & 2.5 & 3.9 & 0.1 & 0.2 & 1.0 & 1.1 & 0.1 & 0.2 \\
\hline total & QE1 & -6.8 & $-12.4^{*}$ & -15.0 & $-0.6^{* *}$ & $-0.8^{*}$ & $-4.6^{*}$ & -3.8 & $-0.7^{* *}$ & -0.6 \\
\hline total & QE2 & 0.1 & -1.6 & -6.5 & 0.0 & 0.1 & -1.7 & -2.0 & -0.0 & 0.1 \\
\hline total & QE3 & 0.0 & 0.4 & -1.0 & 0.0 & 0.0 & -0.2 & -0.5 & 0.0 & -0.1 \\
\hline
\end{tabular}

Notes: The table shows changes (in basis points) in the two-year OIS rate, in the two-year and ten-year yields, and in alternative estimates of the expectations component of the ten-year yield on LSAP announcement days. * and ** indicate significance at the five- and one-percent level, respectively. "Volatility" denotes the standard deviation of daily changes over the entire sample period. The last three rows for each country show the cumulative changes over all events in each LSAP program. 
Table 5: Summary of event study results

\begin{tabular}{l|l|l|c|c|c|c}
\hline \hline Country & Pref. models & Program & $2 \mathrm{y}$ & $10 \mathrm{y}$ & Abs. change exp. & Rel. change exp. \\
\hline U.S. & RW, R-BIC, R-CP & QE1 & -42.7 & -122.8 & $-78.5[-107.2,-55.0]$ & $64 \%[87 \%, 45 \%]$ \\
& & QE2 & -6.9 & -22.7 & $-15.7[-17.6,-13.9]$ & $69 \%[77 \%, 61 \%]$ \\
& & QE3 & -4.4 & -14.3 & $-9.7[-12.7,-7.1]$ & $68 \%[89 \%, 50 \%]$ \\
\hline Canada & RW, R-BIC, UR & QE1 & -42.5 & -66.3 & $-50.1[-58.3,-45.3]$ & $76 \%[88 \%, 68 \%]$ \\
& & QE2 & -5.2 & -6.8 & $-5.6[-6.6,-4.8]$ & $82 \%[98 \%, 71 \%]$ \\
& & QE3 & -9.4 & -11.9 & $-9.9[-11.6,-8.4]$ & $83 \%[97 \%, 71 \%]$ \\
\hline Germany & RW, UR, R-BIC & QE1 & -12.7 & -53.9 & $-30.2[-51.3,-18.8]$ & $56 \%[95 \%, 35 \%]$ \\
& & QE2 & -9.5 & -12.5 & $-9.8[-12.5,-8.3]$ & $79 \%[100 \%, 67 \%]$ \\
& & QE3 & 0.0 & 6.5 & $4.3[2.4,7.7]$ & $66 \%[38 \%, 119 \%]$ \\
\hline \multirow{2}{*}{ Australia } & RW, R-BIC, R-CP & QE1 & -29.3 & -45.6 & $-25.2[-46.8,-4.7]$ & $55 \%[103 \%, 10 \%]$ \\
& & QE2 & -2.0 & -13.7 & $-4.8[-12.8,0.6]$ & $35 \%[93 \%,-5 \%]$ \\
& & QE3 & -1.5 & -3.9 & $-2.2[-4.1,-0.4]$ & $56 \%[105 \%, 10 \%]$ \\
\hline Japan & BC, OLS, RW & QE1 & -12.4 & -15.0 & $-2.0[-4.6,-0.6]$ & $14 \%[31 \%, 4 \%]$ \\
& & QE2 & -1.6 & -6.5 & $-0.5[-1.7,0.1]$ & $8 \%[26 \%,-1 \%]$ \\
& & QE3 & 0.4 & -1.0 & $-0.1[-0.2,0.0]$ & $7 \%[25 \%,-3 \%]$ \\
\hline \hline
\end{tabular}

Notes: The table summarizes the event study results. It shows, for each country and LSAP program, the cumulative changes in the two-year and ten-year yields, the average, minimum, and maximum absolute changes in the point estimates of the expectations component of the ten-year yield, according to the preferred models, and the corresponding estimates of the contributions of changes in expectations to changes in the ten-year yield (the ratio between the previous two columns). The preferred models for each country are chosen based on their out-of-sample forecasting performance (see last column of Table 3). 
Figure 1: QE1 — decomposition of changes in the ten-year yield

U.S.
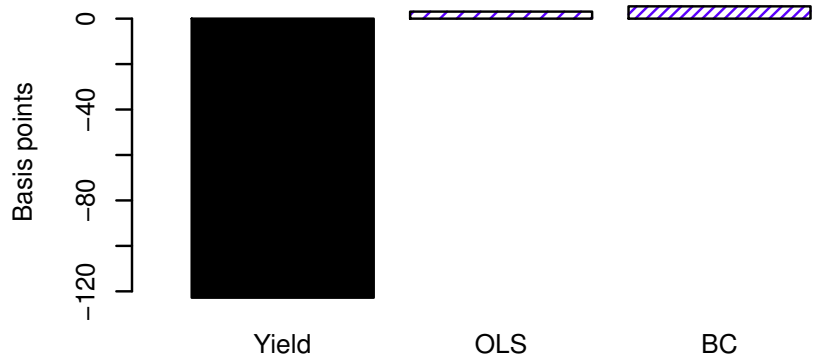

OLS

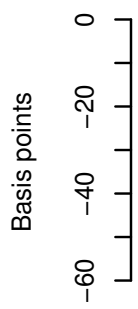

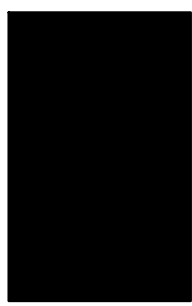

Yield

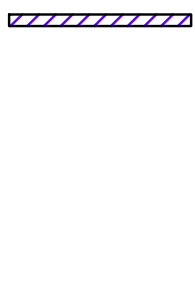

OLS

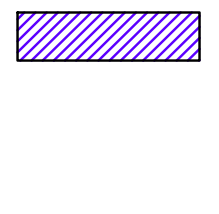

$\mathrm{BC}$

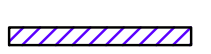

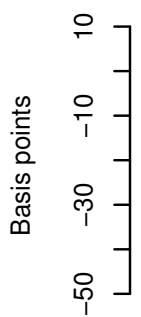

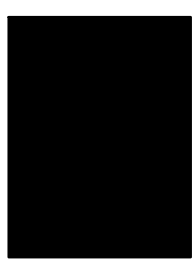

Yield

OLS

BC
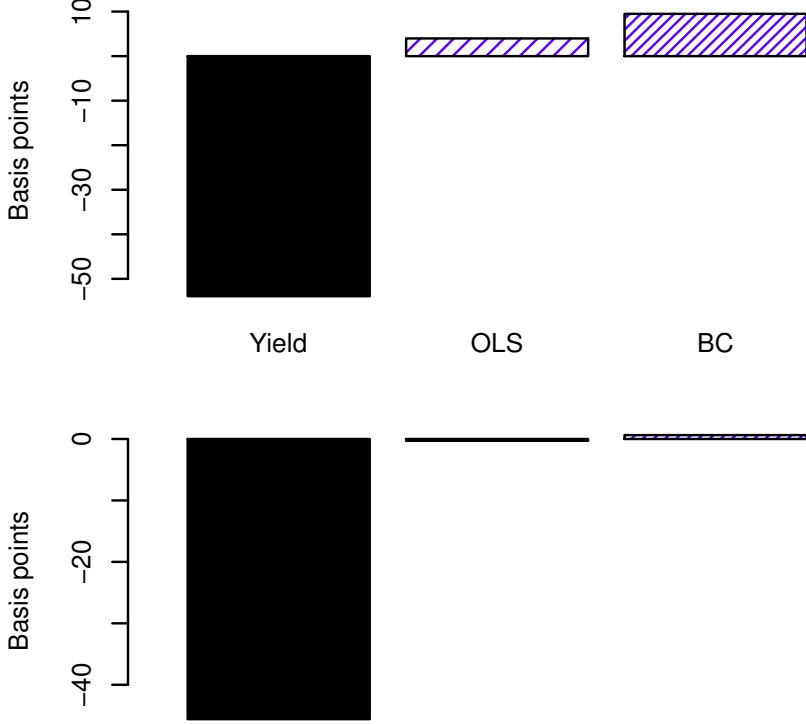

Yield

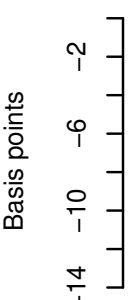

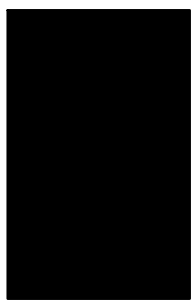

Yield

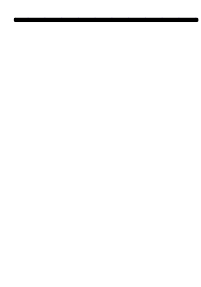

OLS

$\mathrm{BC}$

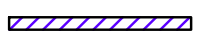

\section{Australia}

BC

RW

UR

R-BIC
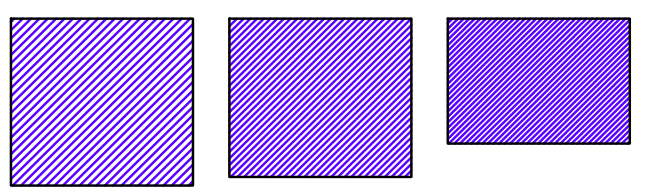

RW

\section{Canada}

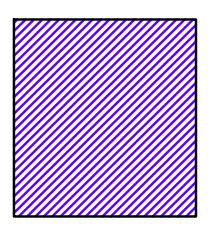

RW

Germany
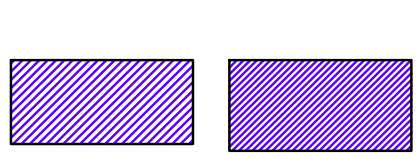

RW

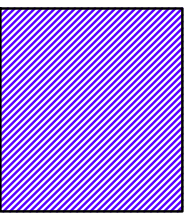

UR

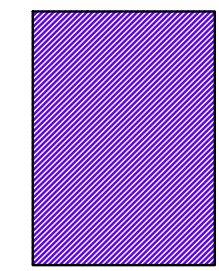

R-BIC

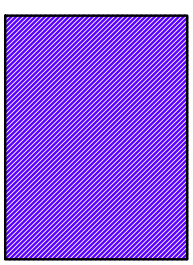

R-BIC

R-CP
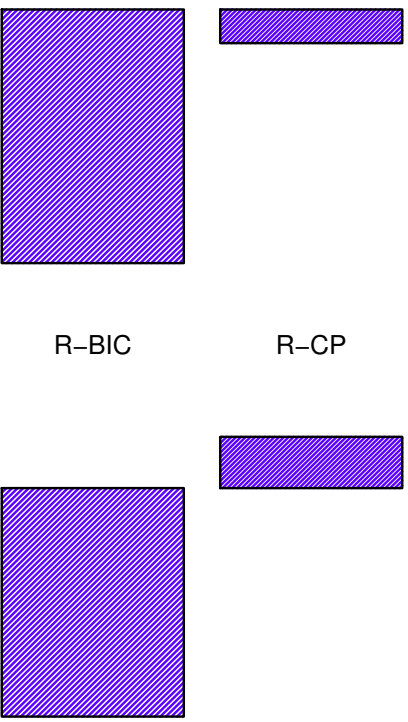

UR

R-BIC

R-CP
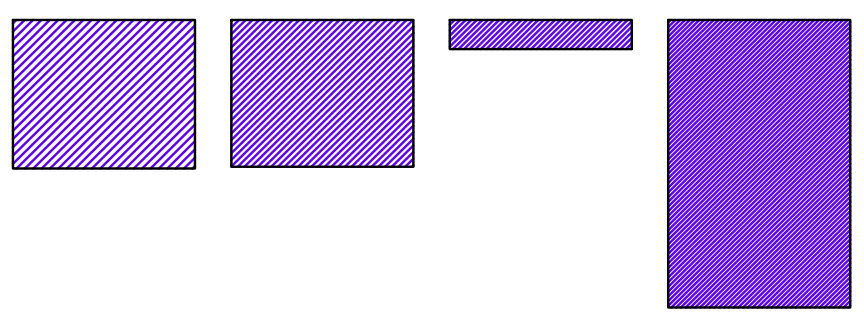

RW

UR

R-BIC

R-CP

\section{Japan}
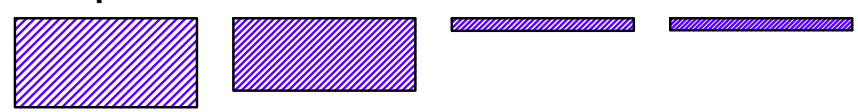

R-CP

Notes: The figure shows the cumulative change in the ten-year yield over the QE1 announcements, as well as the contribution of the expectations component to this change, according to each of the six estimated models. 
Figure 2: QE2 - decomposition of changes in the ten-year yield
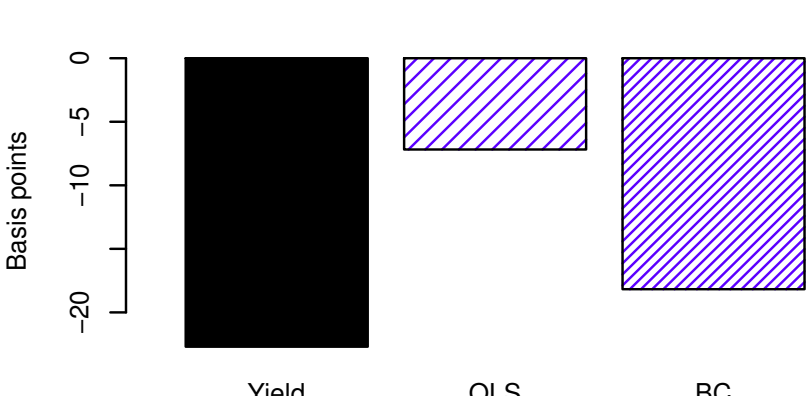

U.S.
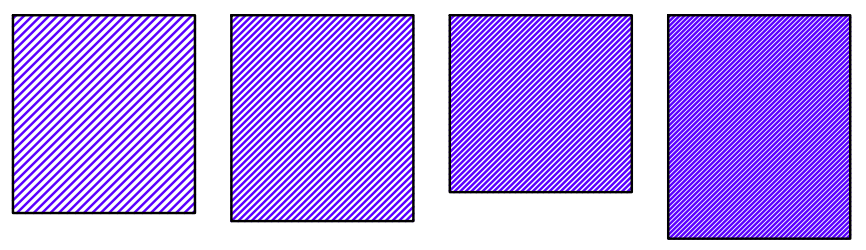

OLS

BC

RW

UR

R-BIC

R-CP

\section{Canada}
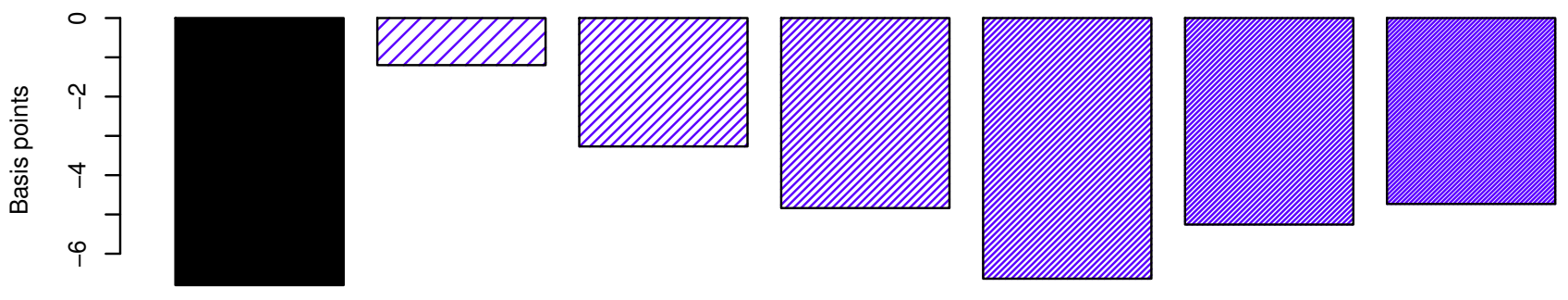

Yield

OLS

BC

UR

R-BIC

R-CP

\section{Germany}

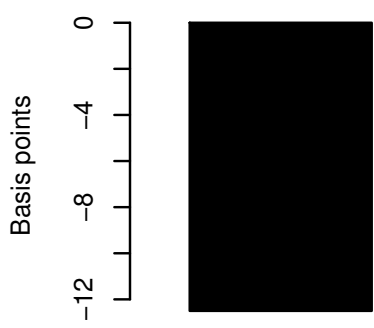

QIIIIIIA WIIIIIIIIA
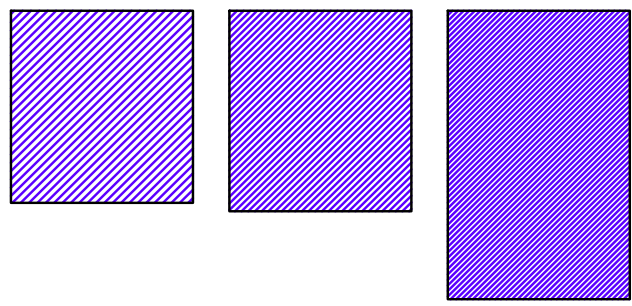

RW

UR

R-BIC

$\mathrm{R}-\mathrm{CP}$

Australia

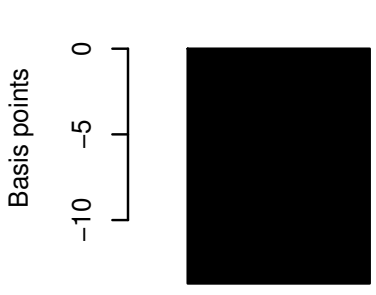

Yield

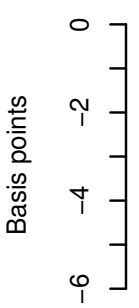
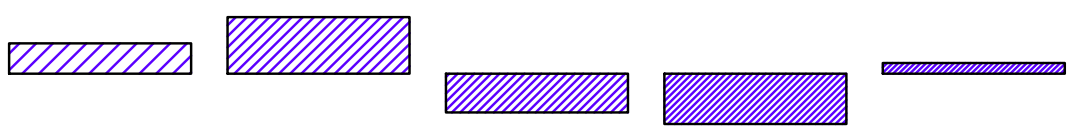

BC

OLS

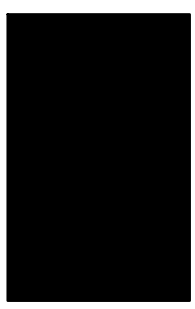

Yield

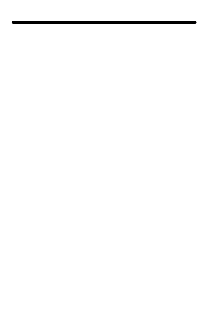

OLS

BC

RW

UR

R-BIC

UR

R-BIC

\section{Japan}

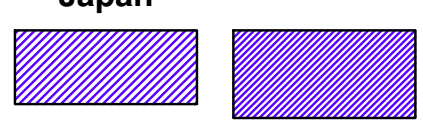

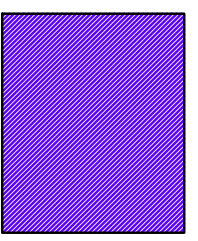

R-CP

Notes: The figure shows the cumulative change in the ten-year yield over the QE2 announcements, as well as the contribution of the expectations component to this change, according to each of the six estimated models. 
Figure 3: QE3 - decomposition of changes in the ten-year yield
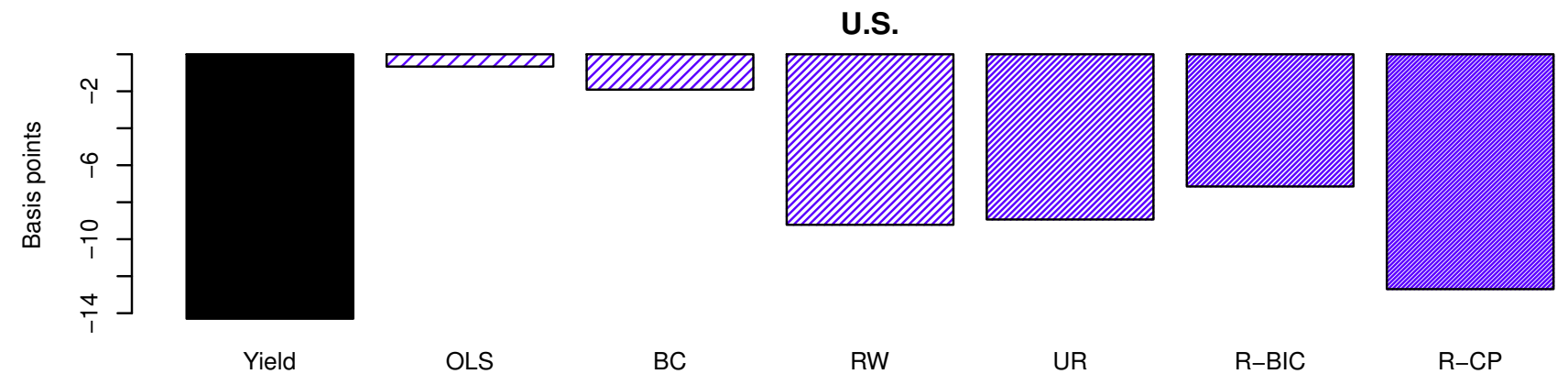

OLS
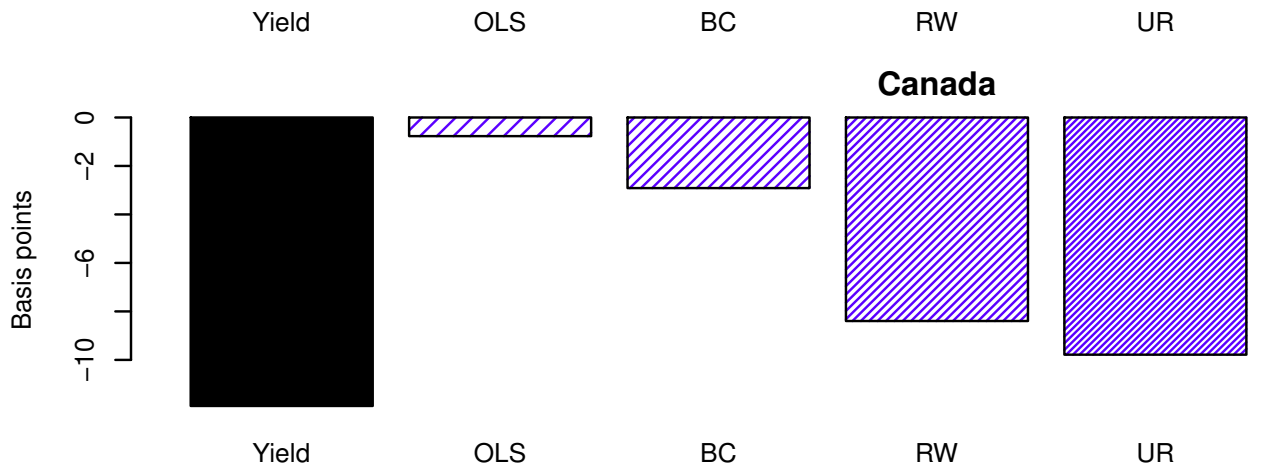

R-BIC

R-CP
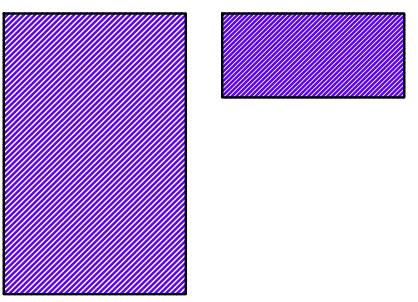

$$
\text { RW }
$$

UR

R-BIC

R-CP

\section{Germany}
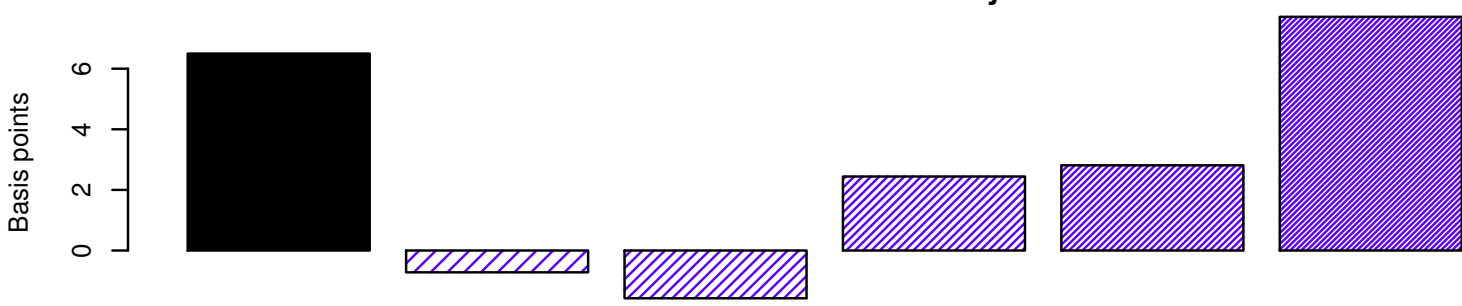

Yield

OLS

BC

RW

UR

R-BIC

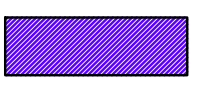

Australia
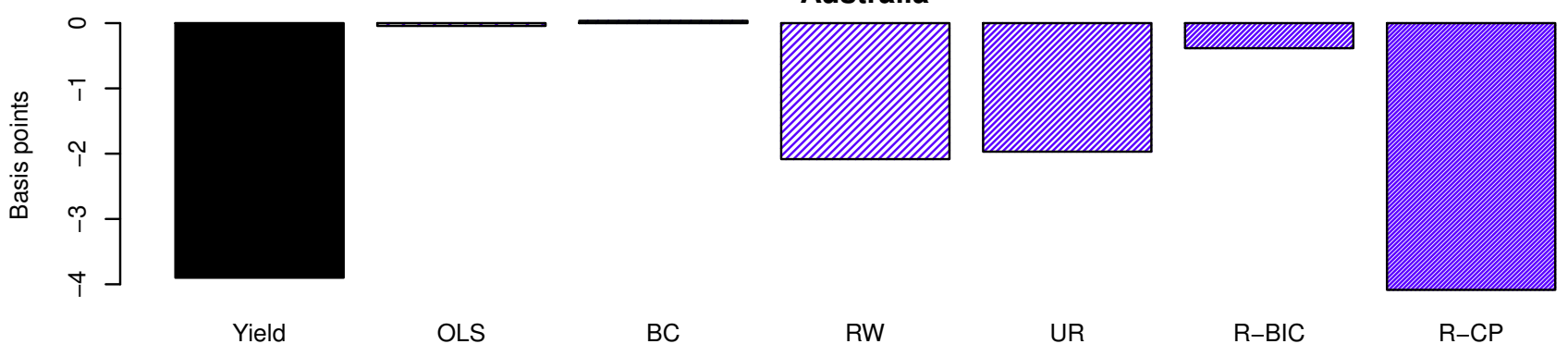

RW

UR

R-BIC

R-CP

\section{Japan}

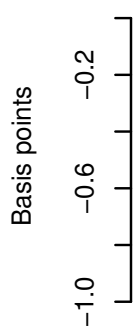
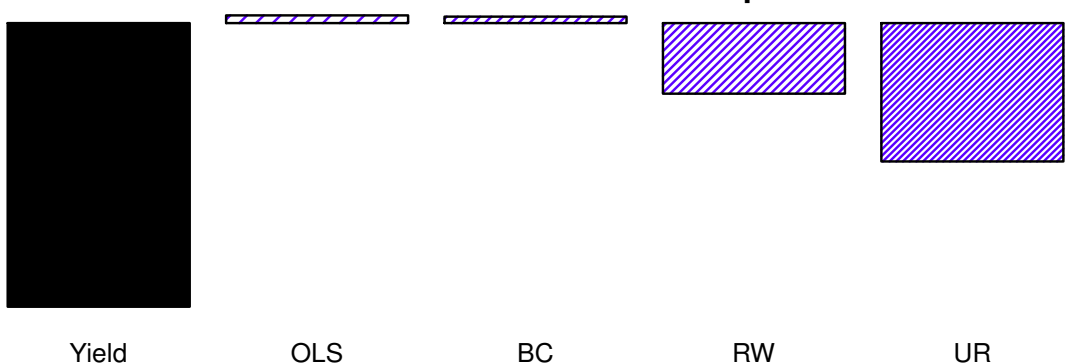

RW

UR

R-BIC

R-CP

Notes: The figure shows the cumulative change in the ten-year yield over the QE3 announcements, as well as the contribution of the expectations component to this change, according to each of the six estimated models. 